\title{
Current knowledge on the mechanism of atherosclerosis and pro-atherosclerotic properties of oxysterols
}

\author{
Adam Zmysłowski iD and Arkadiusz Szterk
}

\begin{abstract}
Due to the fact that one of the main causes of worldwide deaths are directly related to atherosclerosis, scientists are constantly looking for atherosclerotic factors, in an attempt to reduce prevalence of this disease. The most important known pro-atherosclerotic factors include: elevated levels of LDL, low HDL levels, obesity and overweight, diabetes, family history of coronary heart disease and cigarette smoking. Since finding oxidized forms of cholesterol - oxysterols - in lesion in the arteries, it has also been presumed they possess pro-atherosclerotic properties. The formation of oxysterols in the atherosclerosis lesions, as a result of LDL oxidation due to the inflammatory response of cells to mechanical stress, is confirmed. However, it is still unknown, what exactly oxysterols cause in connection with atherosclerosis, after gaining entry to the human body e.g., with food containing high amounts of cholesterol, after being heated. The in vivo studies should provide data to finally prove or disprove the thesis regarding the pro-atherosclerotic prosperities of oxysterols, yet despite dozens of available in vivo research some studies confirm such properties, other disprove them. In this article we present the current knowledge about the mechanism of formation of atherosclerotic lesions and we summarize available data on in vivo studies, which investigated whether oxysterols have properties to cause the formation and accelerate the progress of the disease. Additionally we will try to discuss why such different results were obtained in all in vivo studies.
\end{abstract}

Keywords: Cholesterol, Atherosclerosis, Oxysterols, Cholesterol oxidation, LDL

\section{Background}

Despite a significant focus of many researchers on atherosclerosis in humans, the mechanisms of this disease are still not fully understood. Complications occurring in direct connection with atherosclerosis represent a leading global cause of death and disability [1]. Numerous studies have shown that elevated serum lowdensity lipoprotein (LDL) with sedentary habits is the crucial factor for the initiation and progression of atherosclerosis [2]. However, it is important to define other risk factors, which could influence both the development and progression of atherosclerosis, beyond genetic factors and high LDL cholesterol. Based on cellular and molecular interactions in the formation of atherosclerotic lesions, researchers suspect several proatherosclerotic factors. One recently featured is a high

* Correspondence: a.zmyslowski@nil.gov.pl

National Medicines Institute, Department of Spectrometric Methods, 30/34 Chełmska, 00-725 Warsaw, Poland concentration of oxidized forms of cholesterols - oxysterols - in the blood [3-9]. Additionally, it has been proven that oxysterols can be formed from cholesterol in food, during storage or cooking. Elevated temperature, which is almost always used to prepare meals, accelerate the oxidation process of cholesterol. For this reason oxysterols from the dietary sources, introduced to human body and to the blood stream, can play a key role of progression of atherosclerosis. Yet, despite increasing in vivo studies, obtained results are divergent, thus the final conclusion about the pro-atherosclerotic properties of oxysterols cannot be drawn. In this review we present current knowledge about the mechanism of atherosclerosis, which tries to presenting, which part of this disease oxysterols are involved. Furthermore, we present data from studies suggesting pro- or anti-atherosclerotic properties and discuss why the differences between the received results have occurred. 


\section{Current knowledge on the mechanism of atherosclerosis}

Before we describe the pro-atherosclerotic properties of oxysterols in detail, we have to highlight current knowledge on the mechanism of atherosclerosis. It seems to be the essential aspects to explain the sterols and oxysterols role in development of this civilisation disease.

\section{The role of endothelium cells. Laminar flow and its anti-atherosclerotic properties}

Atherosclerosis is a disease that affects the multifocal repetitive regions of the arterial tree. The formation of this disease begins in the most vulnerable sites (near the branch points and along the inner curvature or regions in which the uniformity of the blood flow is somehow disturbed [10]) by the abdominal aorta, coronary arteries and iliofemoral arteries [11]. Impaired laminar flow induces a small and oscillating shear stress on the artery wall, where endothelial cells (EC) may react by different mechanosensors (PCAM-1/VE-cadherin/VEGFR2) to this mechanical stress [12]. An endothelial cell responses to shear stress by increased synthesis of vasoactive mediator - nitric oxide (NO) to control vascular tone, which causes an immediate reduction in shear stress. Additionally, the cell reacts by secrete extracellular matrix proteins and matrix metalloproteinases to promote remodelling and repair, and with expression of growth factors, e.g. TGF- $\beta$, to control cell survival and proliferation [13]. However, if the shear stress is still present, through mechanotransduction, the NF- $\mathrm{BB}$ path is triggered as part of the inflammatory process. Elevated NF- $\kappa \mathrm{B}$ activity results in the expression of NF-kBdependent genes, which encode adhesion molecules, such as PCAM-1, ICAM-1, VCAM-1, P-selectin and Eselectin, cytokines: TNF $\alpha$, IL-1, IL-6, IL-12 and growth factors G-CSF, M-CSF [12, 14]. The importance of the NF- $\mathrm{kB}$ pathway in the formation of an atherosclerotic lesion is shown in a study on apoE-knockout mice, in which the applied endothelial-targeted inhibition of NF$\kappa \mathrm{B}$ signalling results in a decrease in the lesion area, which was associated with a decrease in the recruitment of macrophages to the lesion [15]. However, no correlation between decreased lesion area with macrophage NF-kB suppression was found in the study conducted by Kanters et al. (2003) [16].

The discovery and importance of the activation of this nuclear factor gave an idea that atherosclerosis is not a disease strictly connected with the aging process, but rather a chronic inflammatory condition, which after evolving could lead to intimal destruction, arterial thrombosis and end-organ ischemia. Regardless of mechanotrandsuction, turbulent flow also disturbs intercellular tight junctions of the endolethium and causes thinning of the glycocalyx, which could favour migration of low- density lipoprotein (LDL) and white blood cells to the subendothelial intima [17]. Entry of LDL and diapedesis of monocyte and lymphocyte type $\mathrm{T}$ into the intima, begins a cascade leading to the formation of a atherosclerosis lesion. Once formed, the atherosclerotic plaque on the artery wall maintains disturbances in the laminar blood flow, which leads to mechanotransduction and inflammatory activation of nuclear factor NF- $\mathrm{kB}$ in subsequent cells of the endothelium. This mechanism can explain why grown plaque will also build up in time along the vessel (Fig. 1) [11].

\section{The role of LDL and its oxidation in atherosclerosis}

A low density lipoprotein (LDL), which is the main carrier of cholesterol in the human body, plays a key role in the transfer and metabolism of this sterol lipid. Due to the fact that lipoproteins are very heterogeneous groups of particles, concerning size and structure, based on physical and physiological properties, it was defined that LDLs are particles having a density of 1.019$1.063 \mathrm{~g} / \mathrm{ml}$. More specifically, LDL particles have an average diameter of $22 \mathrm{~nm}$, the core is composed of about 170 triglyceride (TG) and 1600 cholesterol esters (CE) of the molecule and a single surface layer containing approximately 700 molecules of phospholipids ( 64\% phosphatidylcholine (PC), 11\% lysphosphatdylydcholine (LPC), $\sim 26 \%$ sphingomieline) and one copy of the apoB-100 $[18,19]$.

After mechanotransduction of the endolethium cells, the LDL penetration to intima is possible. Propound mechanism of LDL penetrating into intima are transcytosis, by vesicular bodies across the endothelial cell $[20,21]$ and sieving through porous pathways between or through the endothelial cells [22]. Mathematical simulation of the atherosclerosis formation supports the idea that passage of LDL is done by sieving via pores through or between endothelial cells $[23,24]$. Losing recognition by LDL receptor by its methylation, did not affect penetrability of the particle though the arterial wall in rabbits, which suggests that transfer of the LDL into intima is not LDL receptor dependent $[21,25]$. In addition, LDL penetrates the arterial wall as intact particles, however surface free cholesterol and phospholipids are probably exchanged between endothelial cells and the LDL particle [26]. After penetrating the arterial wall, particles bind with intimal proteoglycans [27], which may enhance the susceptibility of the lipoprotein to oxidation [28].

After gaining entrance to the intima, LDL undergoes various modifications including oxidation, acylation, lipolysis, proteolysis, aggregation and fusion [29-31]. The main reaction occurring is oxidation, primarily by reactive oxygen species (ROS). Early on, oxidation of the LDL leads to the formation of a minimally oxidized LDL (mmLDL), which demonstrates pro-inflammatory activity. 


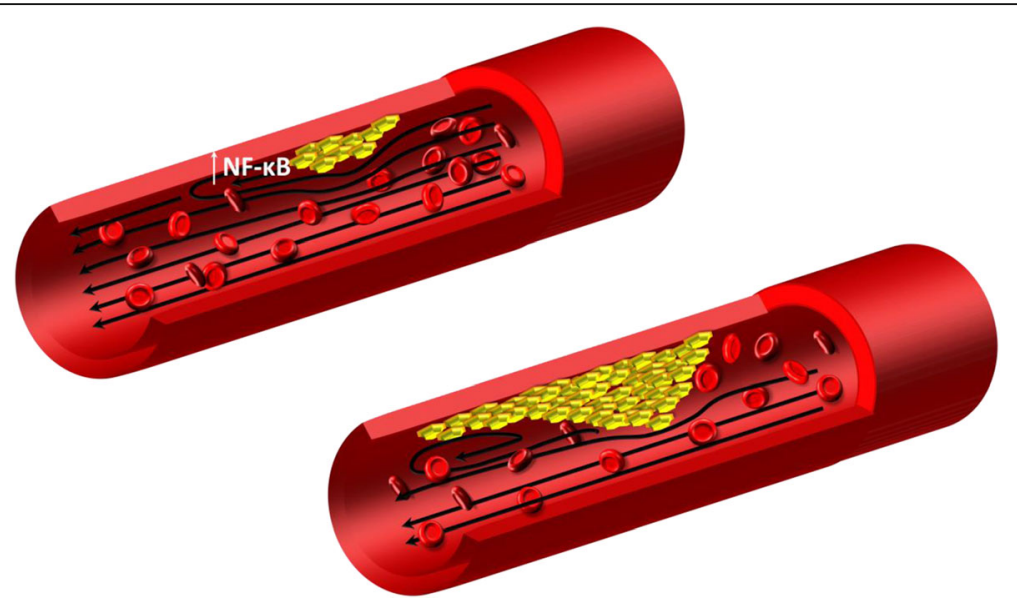

Fig. 1 Laminar flow disturbances. Once formed, lesion, leads to maintaining flow disturbances and activation of NF-kB in subsequent cells

Further oxidation of the mmLDL progresses to form moderately oxidized LDL (moLDL) and finally aggregates of highly oxidized LDL (oxLDL) (Fig. 2). MmLDL, moLDL and oxLDL could be recognized by macrophage scavenger receptors (TLR-4, SR-A1,2, CD36 (SR-B2), CD68(SR-D1), LOX-1(OLR1, SR-E1), FcyRII-R2) [32, 33] and each receptor recognises oxidized LDL in a different state: TLR-4 recognizing oxidized cholesteryl esters of mmLDL; LOX1 and SR-A1,2 recognizes modification on apoB-100 of moLDL and oxLDL; CD36 receptor recognizes oxidized phospholipids of moLDL and oxLDL [34,35]. According to Stanton et al. (1992) [36] high affinity was found in FcyRII-R2 to oxLDL, yet no possible mechanism of its recognition was proposed [36].

Modifications of LDL due to oxidation have a dramatic effect on local vascular homeostasis and endothelial cell cytotoxicity [37], which incite an inflammatory response characterized by the chemokine secretion (CCL2, CCL5), an even higher expression of adhesion molecules by the overlying endothelial cells and the stimulation of macrophages and smooth muscle cells to migration and mitogenesis [38]. The modifications also contribute to lipoprotein aggregation and further promote lipoprotein retention. Additionally, oxLDL have been shown to increase the activity of S-adenosylmethionine-dependent methyltransferases, which lead to increased asymmetric dimethylarginine (ADMA), an endogenous inhibitor of endothelium nitric oxide synthase (eNOS) [39]. The enzyme eNOS is responsible for NO biosynthesis, which, as it was mentioned, is responsible for control vascular tone. NO also has inhibitory properties of inflammation by diminishing endothelial permeability [40], VSMC proliferation and migration [41], platelet aggregation and adhesion [42], and leukocyte adhesion [43].

The main source of ROS is probably 12/15-lipoxygenase, given that mice with a disruption of this enzyme had substantially reduced atherosclerosis [44]. Such studies also conducted by George et al., (2001) [45] demonstrated similar results - the knockout of enzyme production resulted in diminishing LDL oxidation and by this, atherosclerosis development. Alternate modifications are possible by enzymes - secretory sphingomyelinase (SMase), secretory phospholipase 2 (sPLA2) and myeloperoxidase (MPO) [46-48]. Sphingomyelinase may also initiate lipoprotein aggregation, cause increased retention and intensify uptake by macrophages [46].

Given that the majority of compounds (PC and $\mathrm{CE}$ ), included in a LDL particle, mostly consist of at least one unsaturated fatty acid [49], after the ROS have been generated, the chain reaction leading to the formation of CE hydroperoxide and PC hydroperoxide begins. Since the most common unsaturated fatty acid in the LDL is linoleic acid (C18:2) [50], the main products of oxidations are C18:2 hydroperoxide, C18:2 hydroxide, and ketone [51]. LDL contains also oleic, arachidonic, palmitoleic, docosahexaenoic acids [18], so possible oxidation products from those unsatured acids can also occur. Further oxidation can result in the truncation of sn-2 acyl chain, forming short-chain aldehyde or carboxy derivatives. The aldehydes may form adducts with the lysine residues of apoB-100. The 4-hydroxynonenal, a product of truncation of linoleic acid, is one of the most abundant aldehydes in oxidized LDL, which could react with thiols and free amino groups of apoB-100 and cellular proteins [35]. Additionally, formation of one chain of oxidized PC due to hydrophobic interaction between carbon chains could cause it to flip into exterior side of the LDL particle, which may lead to its recognition by macrophage scavenger receptor CD36 [52].

In addition to the oxidation of unsaturated fatty acids, the oxidation of the sterol moiety of cholesterol via the formation of cholesterol peroxides (e.g. 7-hydroperoxycholesterol (7-hpCh), 24-hydroperoxycholesterol) occurs, of which 7-hpCh have the most cytotoxic 


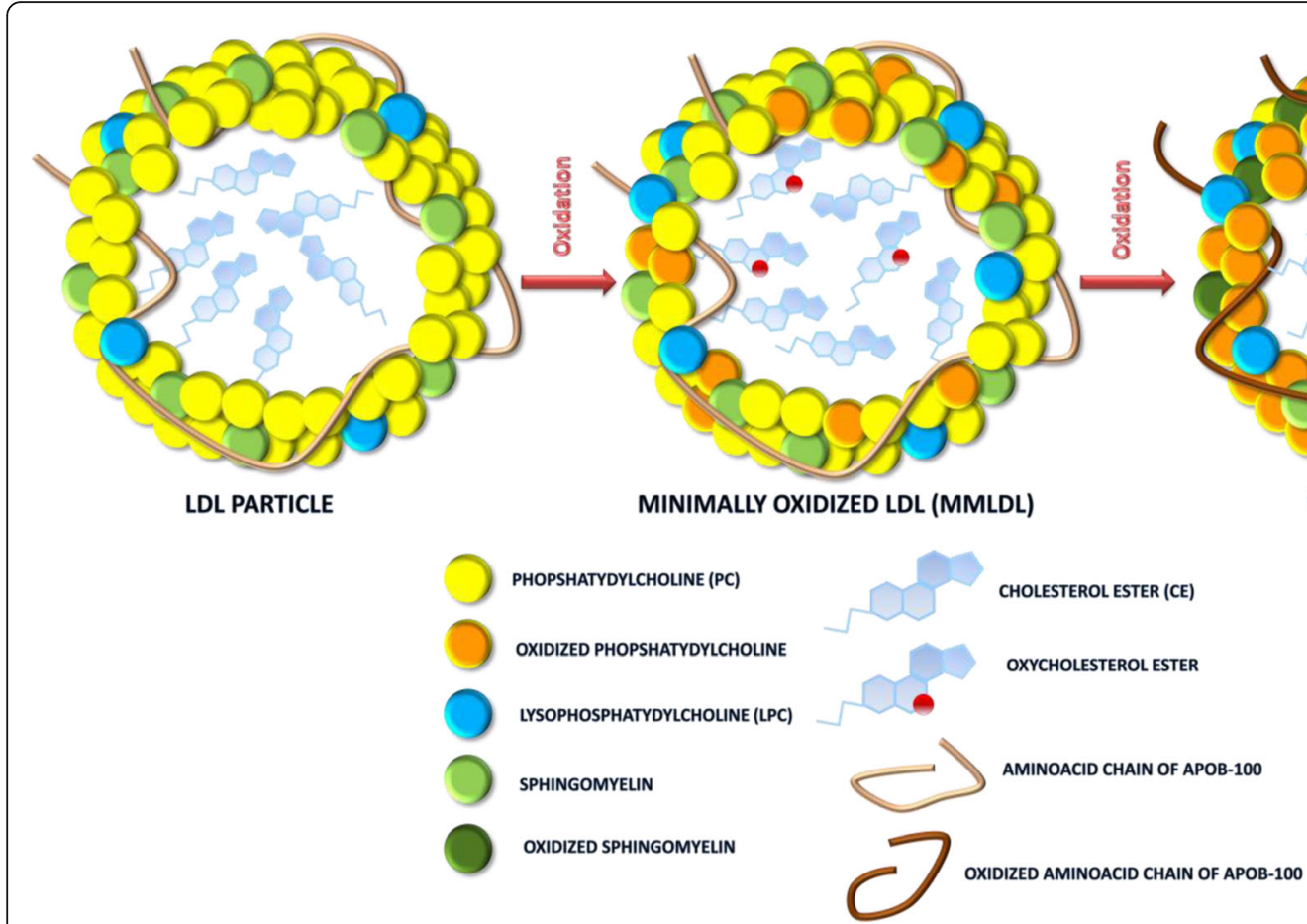

Fig. 2 Possible transformation of a LDL particle due to a reaction with highly reactive oxygen species

properties [53], however, it is rapidly decomposed into 3 relative compounds: $7 \alpha$-hydroxycholesterol $(7 \alpha-h \mathrm{Ch})$, $7 \beta$-hydroxycholesterol $(7 \beta-\mathrm{hCh})$ and 7 -ketocholesterol $(7-\mathrm{kCh})$, which may be found in relatively high concentration in foam cells and fatty streaks [54].

Besides PC, cholesterol and its esters each LDL particle contains one copy of apoB-100 particle. During the oxidation of the LDL, the reaction also occurs on the apoB-100, because it has in its structure amino acids susceptible to being oxidized. ApoB-100 consists of 4536 amino acid residues, which makes it one of the largest monomeric proteins known $[55,56]$. Each VLDL particle contains single molecule of apoB-100, which could be modified and transformed, after the metabolic process in the circulation, into LDL particle. Therefore the lipoprotein apoB-100 needs to be able to adapt to the changes occurring in structure and composition, which take place in the particle; for example, the diameter of a VLDL particle is reduced by approximately 4-10 times after converting to LDL particle. ApoB-100 also has a particular role in maintaining the structural integrity and controlling the interactions of LDL particles [57].

The impact of the oxidation on the oxLDL structure is understood poorly. There is data showing changes arising during the oxidation reaction using free radicals or reactive oxygen species. Studies using LDL particles and usage of copper ions to propagate oxidation show that the main oxidation on the apoB- 100 occurs on the tryptophan and histidine amino acids [58]. This process leads to the formation of oxyhistidine and kynurenine, after the tryptophan conversion. According to Obama et al. (2007) [58] no oxidation occurred on LDL receptor domains in their studies. Using different hydroxyl radical concentrations, Chakraborty et al. (2010) [59], results in the oxidation of Phe, Tyr, Trp, His, Pro and Lys. In the LDL receptor domains (3130-3160 and 3259-3267) [60], Pro3262 oxidation was observed at low peroxide exposure. The results present that even in early stages of LDL oxidation, modifications in secondary structure and physical state of the particle may not be present, although structure of apoB-100 could undergo changes, mainly in tertiary structure, which could be associated with alteration of particle surface [61]. Extensive LDL exposure to reactive oxygen species will cause oxidation of amino acids eventually leading to the modification of the second structure of the protein (primarily in the $\alpha$ helical and then in the $\beta$-structure), which causes the loss of the ability to be recognized by LDL receptors. After significant losses of the structure of apoB-100, the recognition of the particle is taken by the scavenger receptors LOX1 and SR-A1,2 in macrophages [35].

\section{The role of the macrophage derivative from monocytes} As mentioned above, activation of the NF- $\mathrm{kB}$ pathway in endothelium cells leads to an increased production of adhesion molecules VCAM-1, PCAM-1, ICAM-1, Pselectin and E-selectin, which promote the adhesion of monocytes and lymphocytes type $\mathrm{T}$ on the surface of the 
endothelium. Additionally, activated endothelial cells secrete chemoattractants (MCP-1 (CCL2), CCL5) that interact with cognate chemokine receptors on monocytes and promote directional migration to the endothelium [62]. In vivo studies using mice susceptible to atherosclerosis, with genetic deficient in MCP-1 (CCL2) or its receptor, CCR2, have demonstrated significant protection against lesion formation, possibly by a decreased subendothelial monocyte accumulation [63]. After adhesion, leukocytes exploit loosened intercellular junctions and migrate into the intima. Endothelial cells, sensing the presence of the oxLDL, secrete the monocyte chemoattractant protein (MCP-1 (CCL2)) [64, 65], which triggers recruitment of monocytes into the intima. Generated mmLDLs after LDL oxidation stimulate the endolethium to produce a macrophage colonystimulating factor (M-CSF), which causes monocytes to proliferate and differentiate to macrophages. After the macrophages are present, using the scavenger receptors, they rapidly uptake the oxLDL (or after different modification) by phatocytosis. As it was mentioned, the uptake of oxidized LDL probably occurs via the scavenger receptors, especially of the scavenger receptor $(\mathrm{SR}-\mathrm{A} 1,2)$ and type-B family member, CD36 and CD68 [33, 66]. However, studies on apolipoprotein E (ApoE-deficient mice) with deficient gene-targeting indicate that additional mechanisms of foam cell formation are also present in atherosclerosis [67].

Once ingested, the cholesteryl esters of the LDL are hydrolysed in late endosomes to cholesterol and fatty acids [68]. Free cholesterol released from lysosomes and from rehydrolysed cholesteryl ester can also be transported to the plasma membrane and thus be available for efflux out of the cell [69]. Cholesterol efflux is one of major processes involved in plaque regression when hypercholesterolemia is reversed. The free cholesterol can also undergo reesterification to cholesteryl fatty acid esters (the "foam" of foam cells) catalysed by the ER enzyme acyl-CoA:cholesterol ester transferase (ACAT) [70]. Studies show that oxysterols can also undergo reesterification by ACAT. Moreover, the data suggested that one of the oxysterols, $7-\mathrm{kCh}$, may be more suitable to activate the site of the enzyme than cholesterol [71]. On the other hand, the study conducted by Maor and Aviram (1994) [72], presents opposite results. After the uptake of the oxLDL by the J774 cells, a very small concentration of $7-\mathrm{kCh}$ esters was measured and based on that, it was concluded that this oxysterol is not a good substrate for the ACAT enzyme. However, the possible explanation of the received low concentration of the oxysterol ester was limited access to fatty acids available for the esterification reaction [73]. The reason of that was that most of the fatty acids were modified during the copper induced oxidation [74]. Surprisingly, mice ACAT-deficient are still able to develop significant lesions, which suggests that the formation of foam cells is more complex [75].

\section{The role of the vascular smooth muscles cells and progression of the atherosclerosis lesions}

Vascular smooth muscle cells (VSMCs) are a highly specialized cells, whose primary function is to adjust the diameter of the blood vessels and local blood pressure, thereby controlling blood flows in vessels. VSMCs exhibit phenotypic and functional plasticity, mainly by expressing a unique 'SMC markers', including: $\alpha$-smooth muscle actin, smooth muscle-myosin heavy chain, smoothelin- A/B, SMemb/non-muscle MHC isoform-B and cellular retinol binding protein [76]. In case of the vessel damage, VSMCs are able to switch from "normalcontractile" to the 'proinflammatory-synthethic' phenotype [77]. This adjustment results in reduction in the expression of mentioned markers responsible for VSMCs contraction and in the production of proinflammatory mediators, which trigger proliferation and migration, a main processes in the vascular wall repair. Moreover cytokines, shear stress, reactive oxygen species, and accumulated lipids, which are present in formation of atherosclerotic plague, can not only altered VSMCs to proinflamatory phytype, but causing abnormal regulation, which leads to additional VSMC dedifferentiation and increased extracellular matrix formation, such as collagen, elastin and proteoglycans [78]. Present oxidized phospholipids from oxLDL inhibit the Krüppel-like factor 4 causes VSMCs to exhibit smooth muscle-derived cells macrophage' phenotype [79]. However, gene expression of these VSMC-derived macrophage-like cells is definitely different from classical monocytes and macrophages, resulted for example in reduced phagocytic capacity compared with activated peritoneal macrophages.

All process related to unregulated VMSCs - migration, proliferation in the intima, dedifferentiation and the synthesis of extracellular matrix components contribute to progression of the lesion. Accumulated macrophages and migrated VSMCs often die by apoptosis, causing the entering and aggregation of their interior cellular components in the intercellular matrix, which mainly constitute the lipid or necrotic core of the lesion. Local dynamic forces, including circumferential flexion and shear stresses, are main factors, among various, that may destabilize plaques and promote thrombosis [80]. An important factor, which can cause disturbances in the stability of atherosclerotic lesions, is also the possible calcification and neovascularization, common features of advanced lesions. Intimal calcification is associated with pericyte-like cells secreted matrix components, which are subsequently subjected to calcification. This process, 
which is similar to bone formation, is regulated by oxysterols and cytokines [81]. Thrombosis, the ultimate complication of atherosclerosis, is associated with the eruption of plaque, which causes blood coagulation components to interact with tissue factors in the plaque's interior, triggering the thrombus, that could extend into the vessel lumen, where it will interfere or block the blood flow. Furthermore, the thrombus can shear off and block important capillary vessels causing a lack of blood flow and ischemia of the cells or important tissues [82].

\section{The role of oxysterols in atherosclerosis}

As it was mentioned, oxysterols form during the LDL oxidation, after penetrating into intima. However, there is another possibility, from which oxysterols can be found in human body e.g. in plasma. Cholesterol is very susceptible to auto-oxidation, in a reaction, in which free radicals or highly reactive species participate. Due to the exposure of cholesterol to air during heating or longterm storage, it slowly oxidizes to an epimeric mixture of hydroperoxides, which decomposes to $7-\mathrm{kCh}, 7 \alpha-$

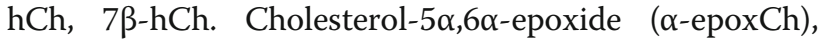
cholesterol-5 $3,6 \beta$-epoxide $(\beta$-epoxCh) are products of epoxidation. The hydration of epoxysterols produces $5 \alpha-$ cholestane-3 $3,5,6 \beta$-triol (triolCh) [83]. There is also a possibility that the side chain oxidizes forming different 20-, 24-, 25- and 27-hydroperoxides and that process often takes place during auto-oxidation of crystalline cholesterol (Fig. 3) [84].
Therefore, oxysterols could be found in various cholesterol-rich foods, even in raw meat, like pork loins, which could be even $0,67 \%$ of total cholesterol content [85]. The content of oxysterols can differ much due to different food, method of its preparing, additionally storage and reheating. The highest oxysterol obtained by Min et al. (2016) [85] was triolCh $(0,6 \mathrm{mg} / 100 \mathrm{~g}$ pork loins) after pan roasting with additional storage and reheating, which sum up with other oxysterols to about $1,36 \%$ of total cholesterol content. The highest oxysterol obtained by Lee et al. (2006) [86], also after pan roasting with additional storage and reheating, was $7-\mathrm{kCh}$ (3,5 mg/100 g beef loins) and taking into account all of the found oxysterols, cholesterol was subject to oxidation in about $6 \%$.

After meal consumption, oxysterols can also be found in human plasma as a result of the absorption of those compounds from intestines [87]. Different absorption rates were achieved by Osada et al. (1994) [88], where only approximately half of the oxysterols was absorbed, comparing to the cholesterol. It was also pointed that absorption rate of individual oxidized cholesterols differed considerably and was approximately $30 \%$ for $7 \alpha$ $\mathrm{hCh}, 42 \%$ for $7 \beta$-hCh, $32 \%$ for $\beta$-epoxCh, $28 \%$ for $\alpha$ epoxCh, $15 \%$ for triolCh and $12 \%$ for $7-\mathrm{kCh}$. It was also pointed out, that increased polarity of triolCh was not correlated with its absorption. A lower solubility of oxysterols in bile salt micelles, a lesser susceptibility of oxysterols to esterification in intestinal mucosal cells, and direct toxic effects on mucosal cells were suspected

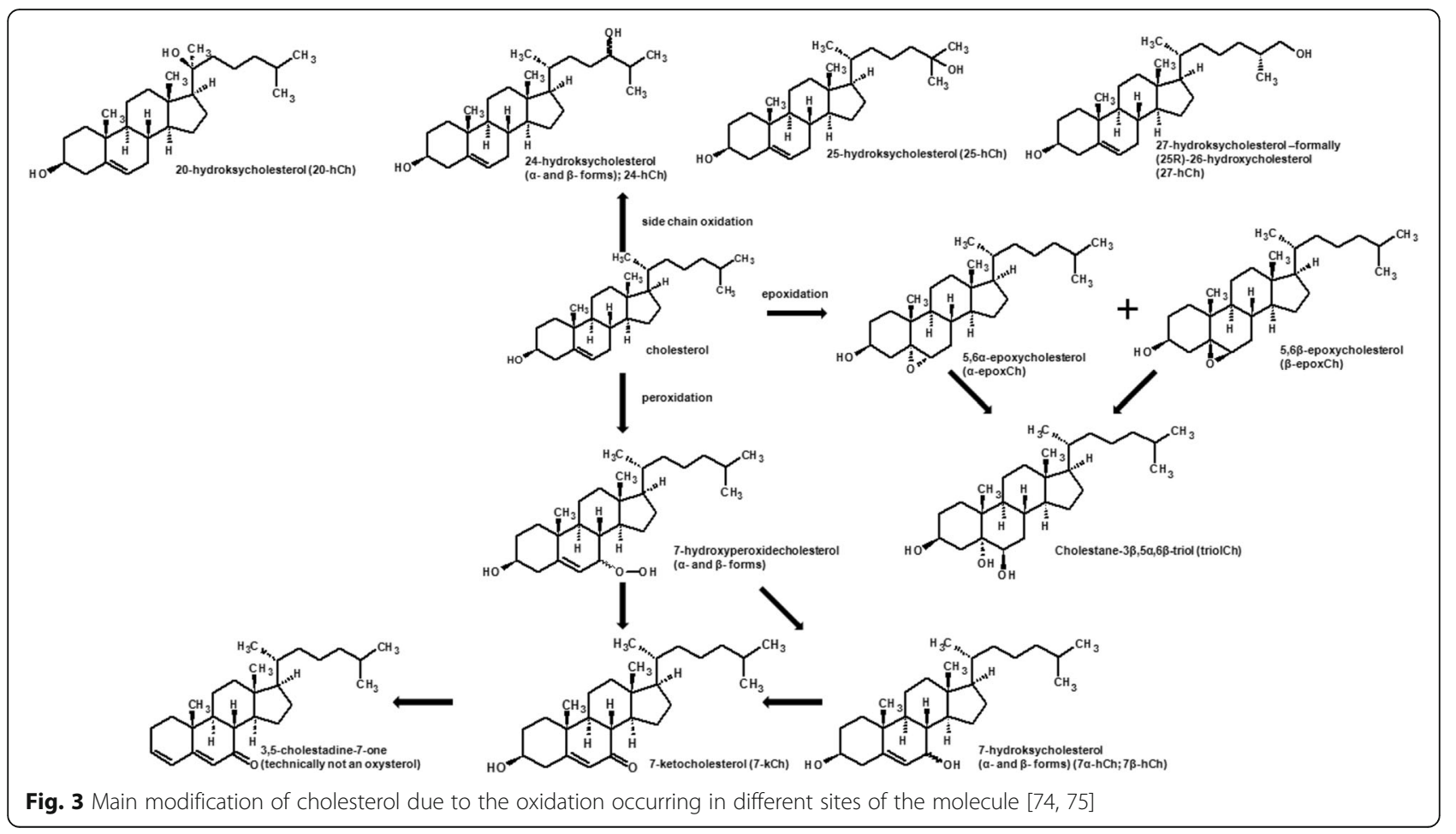


to be reasons for the observed differences [88]. The different absorption rate was also confirmed in a different study conducted by Linseisen and Wolfram (1998) [89], where the highest absorption was obtained by $7 \alpha-\mathrm{hCh}$ and $7 \beta-h C h$ and the lowest with triolCh, which corresponds to results achieved by Osada et al.(1994) [88] However, studies conducted by Krut et al. (1997) and Vine et al. (1997) [90, 91] show that the addition of polar ketone, hydroxide or epoxide moiety to the sterol chemical structure shifts properties of oxysterols to more hydrophilic and by this absorption of these compounds are much more likely than of cholesterol itself. After intestines absorption, oxysterols are mainly transported in plasma bound with albumin or carried by lipoproteins [92]. Oxidized cholesterol are secreted from enterocytes into lymph as incorporated in chylomicrons or chylomicrons remnants at first, yet after chylomicrons regonision by the lipid receptors in hepatocystes, they are passed to VLDL and HLD fraction. VLDL in the circulation is converted via hydrolysis of constituent lipids into smaller LDL particles [87]. So, mainly oxysterols circulate in blood stream in LDL and HDL fraction and in this state they can stay in the human body for a long time [93], which means that the increased polarity does not alter the distribution between different lipoproteins fraction, it is similar to that of cholesterol [94]. Reported oxysterol data in biological samples includes nine oxysterols measured in human plasma, namely: 7$\mathrm{kCh}, 7 \alpha-\mathrm{hCh}, 7 \beta-\mathrm{hCh}, \alpha$-epoxCh, $\beta$-epoxCh, triolCh, 24-hydroxycholesterol (24-hCh), 25-hydroxycholesterol (25-hCh) and 27-hydroxycholesterol (27-hCh) [95]. Additionally, some oxysterols $(7 \alpha-h C, 24-h C h, 25-h C h$, $27-\mathrm{hCh}$ ) are biosynthesized in cells by specific enzymes in cytochrome P-450, which are mainly used in the human organism for the conversion into bile acids [96].

Whether oxysterols possess atherogenic properties, their complete removal from the human body is impossible and the question still remains, what oxysterols cause in connection with atherosclerosis, after entering the human body. Cytotoxicity, inducing inflammation, apoptosis and phospholipidosis are confirmed properties of oxysterols on vascular cells [97-99]. Additionally, Sentzu et al. (2012) [100] proved that oxysterols may affect control stiffness in the endothelium cells, after their incorporation into the cell membrane, which may be important in the initiation of the disease. However, due to the fact that atherosclerotic lesions appear in repeating areas, where the laminar flow is somehow disturbed, it suggests that the effect of oxysterols in initial stage of the disease is lower than the presence of the shear stress. Probably oxysterols have much higher effect on already formed atherosclerotic lesions. Because, mainly oxysterols are transported with LDL particle, thus it is possible to diffuse those LDL-oxysterol containing particles into the intima at any point of the formation of atherosclerosis lesion. Based on research conducted by the Vine et al. (1998) [101] LDL containing oxysterols makes lipids more prone to oxidation. Additionally, Staprans et al. (2003) [93] proved that the whole LDL molecule containing oxysterols is more susceptible to reaction with reactive oxygen species. Hence the introduction of the LDL particles may result in oxysterols comprising accelerating the oxidation of LDL to oxLDL and then absorbed by the macrophages. Based on research conducted by Gelissen et al. (1996) [71] the enzyme ACAT catalyzing production of "core" of foam cells can be more likely to esterify oxysterols than cholesterol, and this formation of lesion could be faster when the oxysterol content is higher. In addition, oxysterols may also act at a later stage of the disease. Sato et al. (2012) [102] proved that oxysterols may affect the acceleration of destabilization and rapture of formed lesion. Similar destabilization effects was found by Gargiulo et al. (2016) [103] in apoE ${ }^{-/-}$mice feed oxysterols, which was prevented when oxysterols absorption was inhibited.

Based on the mechanism of formation of lesion, it seems that oxysterols probably mostly accelerate already formed changes in a blood vessel. The in vitro research and in vivo test on animals should provide data to finally prove or disprove the thesis about the properties of oxysterols. Yet, despite dozens of available publications, results are divergent, thus the study about pro- or not atherosclerotic properties, is still not resolved.

\section{Data analysis of studies on oxysterols}

Prior to in vivo research, essential information of oxysterols properties can be provided using established cell cultures. To investigate whether oxysterols can have an effect on the development of atherosclerosis, study their effect on cells whose involvement in this disease is certain, ie, endothelial cells, smooth muscle cells, macrophages and lymphocytes, should be conducted. Numerous research have shown that oxysterols can significantly induce apoptosis or may cause necrosis on vascular cells [104-106]. Additionally, several cell death mechanisms have been proposed, including: early cytoplasmic membrane modification, cholesterol replacement in membranes by oxysterole associated with disturbances in their essential properties [107], calcium influx [108], overproduction of oxygen radicals [109], loss of transmembrane mitochondrial potential [110], a mitochondrial release of various proteins (cytochrome c, apoptosis-inducing factor, and endonuclease G) into the cytosol [111-114], bcl-2 protein downregulation [115], activation of different caspases (caspase $-3,-7,-8$ and -9), internucleosomal DNA fragmentation, and condensation and/or fragmentation of the nuclei $[112,114,116,117]$. 
Unfortunately majority of available data on effects of oxidized cholesterol on cells are conducted using only single oxysterol. In order to more precisely mimic influence of oxysterols on human vessel cells, after ingestion of oxysterol from dietary sources, in vitro studies should be performed using oxysterol mixtures. Data result from such experiments are available, however inconsistent results were obtained. Larsson et al., (2006) [118] using a mixture of two (concentration $21 \mu \mathrm{mol} / \mathrm{L}$ consisted of $7-\mathrm{kCh}(63,9 \%): 7 \beta-\mathrm{hCh}(36,1 \%))$ resulted in induction of necrosis, however mixture of four oxysterols (concentration $21 \mu \mathrm{mol} / \mathrm{L}$ consisted of $33.3 \%$ 7-kCh: $7 \beta-\mathrm{hCh}$ (18,9\%): $27-\mathrm{hCh}(45,7 \%): 25-\mathrm{hCh}(2.0 \%))$ had proapoptotic effect on macrophage cells. In addition, he demonstrated that the use of the four oxysterols exhibit synergistic effect in triggering the apoptosis process. However, Biasi et al., (2004) and Leonarduzzi et al., (2004) $[119,120]$ usage of a mixture of $7-\mathrm{kCh}(35 \%), 7 \alpha-$ hCh (5\%), 73-hCh (10\%), $\alpha$-epoxCh (20\%), $\beta$-epoxCh (20\%), triolCh $(9 \%)$, and $25-\mathrm{hCh}(1 \%)$ resulted in no cytotoxic effects.

The reason for receiving contrary results, in the case of oxysterols mixture, is probably due to its different composition. However already in vitro studies point out that the issue of the influence of oxidized forms of cholesterol in formation and progression of atherosclerosis is extremely complex, even before consideration of available data from in vivo studies. These data from studies, which were carried out in vivo on various animal models, are summarized in Table 1. Such comparison was already done in 1999 by Brown and Jessup [121], however, since this time a few more studies, which tried to investigate atherosclerotic properties, were conducted.

Jacobson et al., (1985) [122] described the investigation of the properties of triolCh fed to pigeons. Animals were divided into two groups: a control group and group fed a diet containing triolCh for three months. The assumption that triolCh has atherosclerotic properties was drawn from a comparison of calcium accumulation and artery stenosis in both groups. In the group supplemented with oxysterol, the accumulation of calcium and observed narrowing of the aortic lumen was $42 \%$ and $87 \%$ greater than in the control group, respectively. Unfortunately there is no data available on triolCh - its purity or the synthesis pattern, which should provide data if there was a possibility of additional oxysterols administration to animals.

Further results suggesting the atherosclerotic properties of oxysterols after a test using rabbits as an animal model were submitted by Mahfouz et al., (1997) [123]. The test was performed by dividing animals into 3 experimental groups: a control group, a group with an addition of $0.5 \%$ cholesterol and a group with an addition of $0.5 \%$ cholesterol containing a high content of oxysterols. After 11 weeks, staining of dissected rabbit aortas was conducted, which revealed that in the groups supplemented with sterols, thickening of the aorta wall was observed, while in the control group such thickening did not occur. In addition, in the group with administered oxidized forms of cholesterol, the thickening of the wall was greater compared to the group with a diet containing pure cholesterol. Furthermore, the composition of the mixture of oxysterols was examined and the presented results deviate much from every composition of oxysterols in similar in vivo studies. The most abundant oxysterols were $7-\mathrm{kCh}, 26-\mathrm{hCh}$ and triolCh, which suggests that the main oxidation reactions of cholesterol were peroxidation in carbon $\mathrm{C} 7, \mathrm{C} 26$ and epoxidation of double bond C5-C6. As mentioned above, due to the high temperature, the main reactions of the oxidation of cholesterol are the peroxidation of carbon $\mathrm{C} 7$ with a transformation to $7-\mathrm{kCh}, 7 \alpha-$ and $7 \beta$-hCh, the peroxidation of $\mathrm{C} 25$ with a transformation to $25-\mathrm{hCh}$ and the epoxidation of C5-C6 carbon to form $\alpha$ - and $\beta$-epoxCh. Therefore the content of the oxysterol mixture received by Mahfouz et al., (1997) [123] has to be related to a very long exposure of cholesterol to the atmosphere (cholesterol standard 15 years old). It should also be noted that such a long exposure to the atmosphere certainly resulted in the formation of other compounds (about 20\%), which were also not identified in this study. Additionally, triolCh, whose measured content was about $25 \%$ in the oxysterol mixture, probably formed from $\alpha$ and $\beta$-epoxCh in acidic conditions [124]. Ultimately, the final conclusion that arises from the Mahfouz study is difficult to compare against other available in vivo studies, due to different oxysterol content administrated to animals.

Similar studies were carried out by Staprans et al., (2000) [125]. The study was conducted with the use of genetically modified mice: $\mathrm{LDLR}^{-/-}$and $\mathrm{apoE}^{-/-}$, which were divided and fed in two distinct groups: a control diet - containing 1.0\% cholesterol and a diet contained $5-10 \%$ of cholesterol oxidation products. After the end of the study (7 and 4 months for $\mathrm{LDLR}^{-/-}$and apoE ${ }^{-/-}$, respectively) animals in the group supplemented with oxysterols contained over 30\% more atherosclerotic lesions. Similar results were obtained by Staprans et al., (1998) [126] in a study conducted with rabbits. The $100 \%$ increase in the proportion of atherosclerotic lesions in aortas in the group supplemented with oxysterols was achieved compared to the control group. However, in both studies, oxysterols administered to the animals were produced by heating cholesterol at a temperature above $100{ }^{\circ} \mathrm{C}$, without any purification process of the transformed oxysterols. In those studies conducted by Staprans et al., $(1998,2000)[125,126]$ about $50 \%$ of the oxysterol mixture were compounds of unknown structure. 


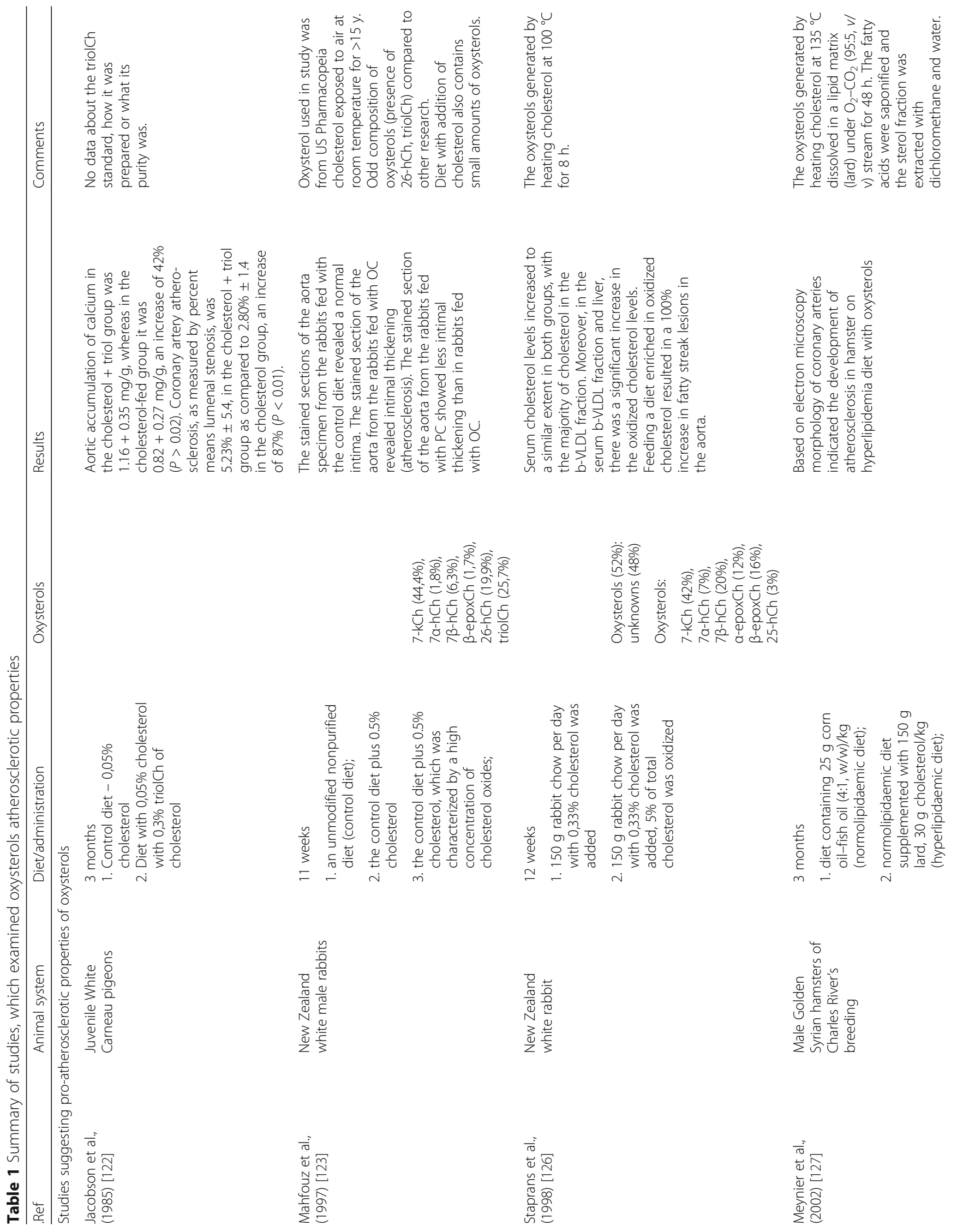




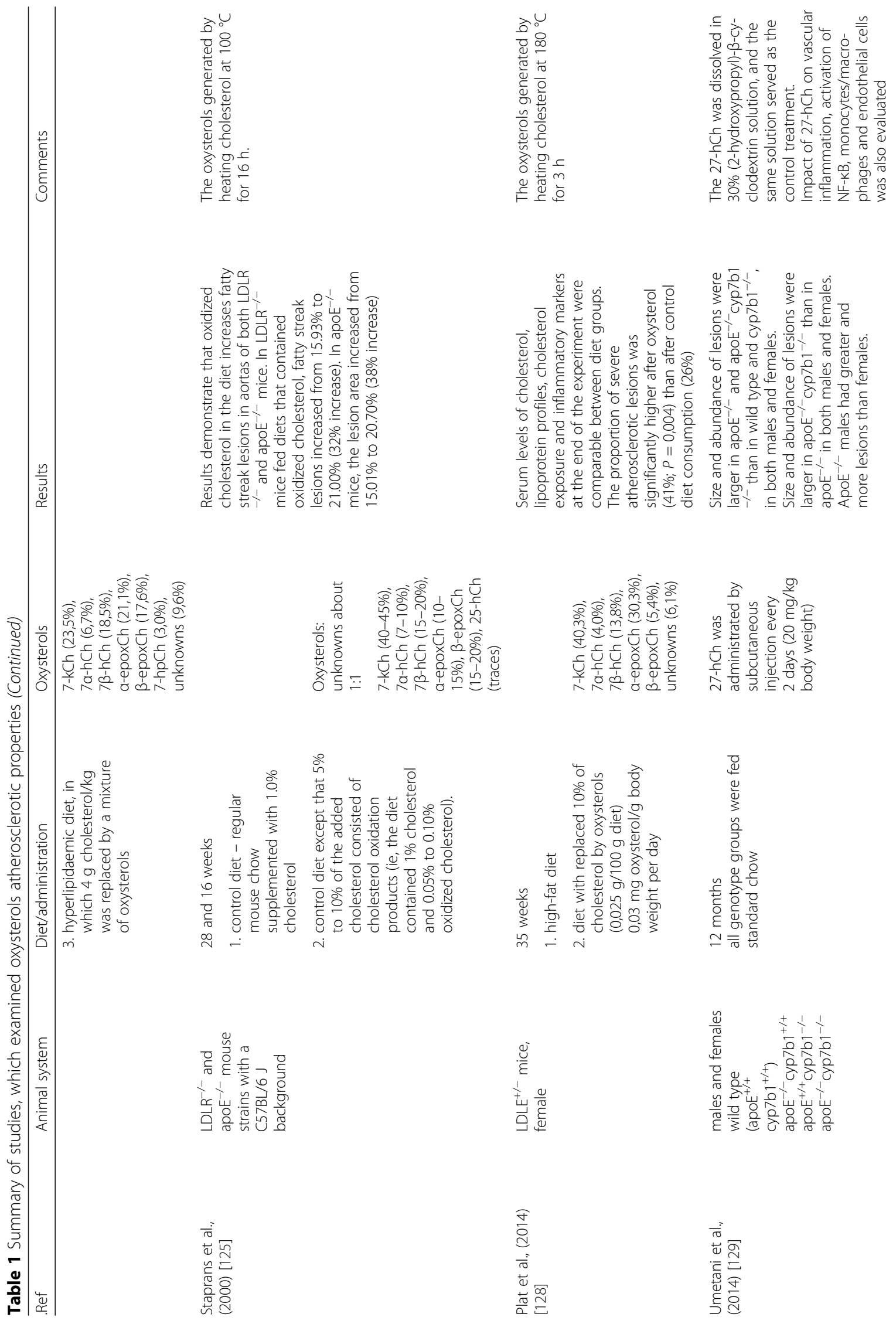




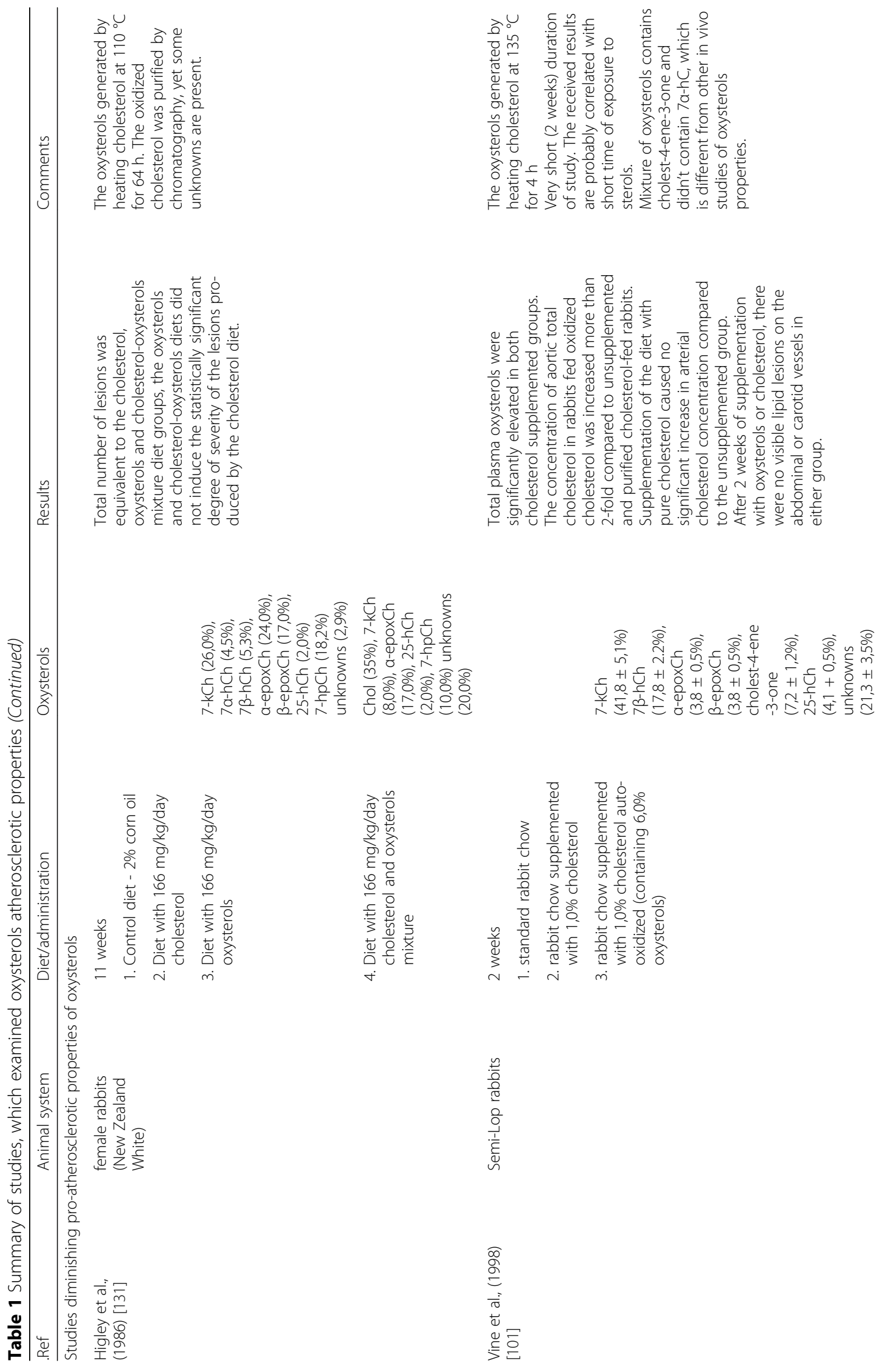




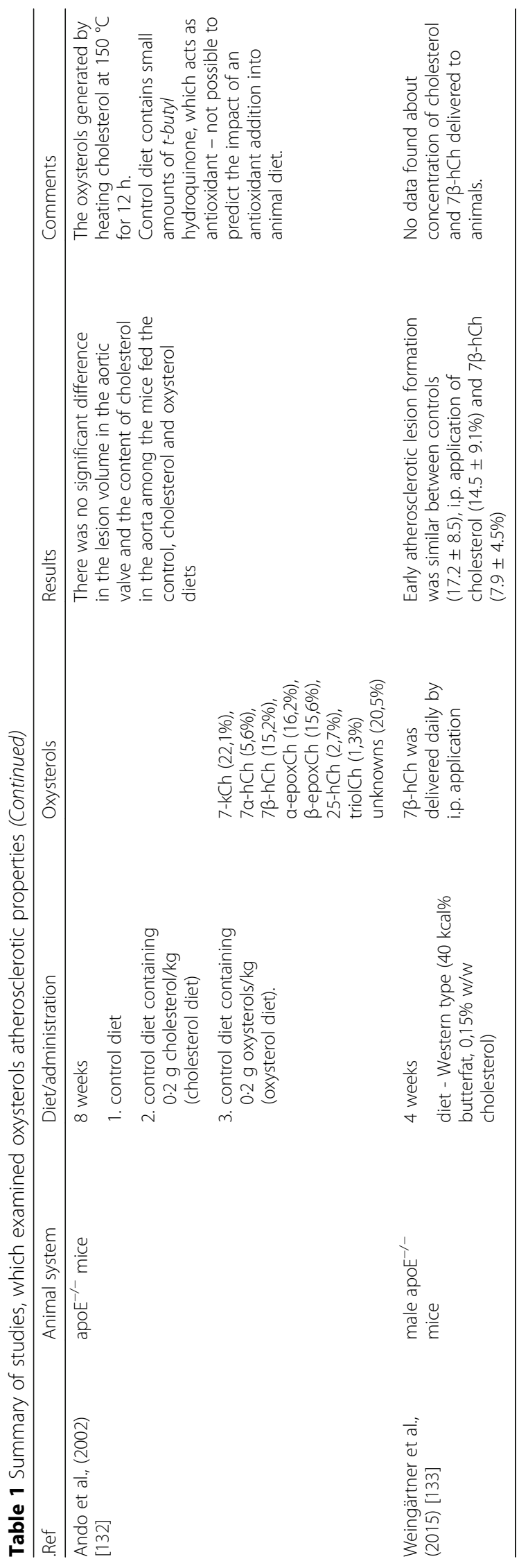


The atherogenic properties were also confirmed by Meynier et al. (2002) [127], using hamsters as a test model. Animals were divided into 3 different diet groups: a control diet, a high-fat diet and a high-fat diet containing added oxysterols. After the test (3 months), based on observation using an electron microscope, no significant changes in vessel walls were observed in the control diet and the cholesterol diet. However, in the diet containing oxysterols, the morphology of vessels was so different from a normal morphology, that based on this observation, it was concluded that atherosclerosis was present.

Plat et al., (2014) [128] based on the results of his experiment, suggested that oxysterols increase the number of serious atherosclerotic lesions. The study was performed for 35 weeks with genetically-modified LDL receptor mice, which were divided into two groups: a control group and a group with a similar diet, but $10 \%$ of the cholesterol was replaced with a mixture of oxysterols. After the duration of the study cholesterol, lipoprotein cholesterol profile and inflammatory markers were comparable in both groups. However, the number of severe lesions differs by $15 \%$ in the group with oxysterols compared to the control group. From the result obtained by Plat, it can be concluded that oxysterols possess pro-atherosclerotic properties, yet generating oxysterols by heating in high temperature casts doubt on this conclusion. Using oxysterols generated by heating without a cleaning process, makes it possible to administrate mice compound of unknown structure and properties. Such compounds were also foundby Plat et al., (2014) [128], which was about $6.1 \%$ of all oxysterol mixtures.

Umetani et al. (2014) [129] described study of impact of 27-hCh on atherosclerotic formation. Four different genotypes of mice was use in the study: wild type $\left(\mathrm{apoE}^{+/+}\right.$;

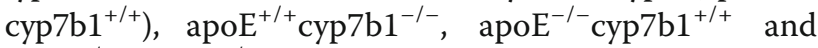

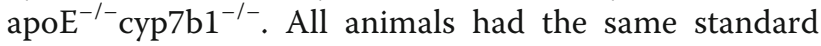
chow and the 27-hCh was administrated by subcutaneous injection every 2 days. After 12 months, the analysis of the amount and severity of atherosclerotic plaques was evaluated. Size and abundance of lesions was larger in $\mathrm{apoE}^{-1-}$ and apoE $\mathrm{E}^{-/-} \mathrm{cyp}_{\mathrm{b}} \mathrm{b1}^{-/-}$groups compared to wild type and in cyp7b1 $1^{-1-}$ group, in both males and females. Additionally, lesions were larger in $\mathrm{apoE}^{-/-} \mathrm{cyp} \mathrm{b} 1^{-1-}$ than in $\mathrm{apoE}^{-/-}$, in both males and females. Interestingly, apoE ${ }^{-/-}$males had greater and more lesions than females, which is probably related to protective actions of estrogen [130]. It should be pointed out that such impact of oxysterol on different gender was not tested in others in vivo study. In addition, it was proven that $27-\mathrm{hCh}$ invokes proinflammatory processes in vascular cells both in vitro and in vivo. Macrophage accumulation in the vascular wall was also increased by $27-\mathrm{hCh}$, proinflammatory genes were upregulated, and plasma TNF$\alpha$ was elevated. Each result obtained by Umetani study confirmed that increases of the occurrence of aorta atherosclerosis is related to $27-\mathrm{hCh}$ presence in plasma. However conducted study is unique due to usage $27-\mathrm{hCh}$, an endogenous oxysterol, which could be found in plasma, because it is synthesized in human body by bile enzyme CYP27A1 [96]. Unfortunately it is not possible to compared these result with other studies investigating oxysterols, because they are focused on oxysterols, which do not form in a healthy human body.

In another study Higley et al., (1986) [131] investigated the properties of oxysterols fed to rabbits. Animals were divided into 4 different groups: a control diet, a diet high amount of cholesterol, a diet high amount of oxysterols and a diet high amount of cholesterol and an oxysterol mixture. After 11 weeks, there was no observed difference in the amount and severity of plaque in groups fed with sterols. As in other described studies, oxysterols were produced by heating cholesterol above $100{ }^{\circ} \mathrm{C}$, yet it is worth mentioning that it was the first time that oxysterols were used after a purifying process using preparative chromatography. Unfortunately, although the cholesterol was submitted to a purification process, the content of unknown compounds in the cholesterol/ oxysterol mixture was about $20 \%$.

Vine et al., (1998) [101] on the basis of the conducted research using rabbits as an animal model, verified if oxysterols possess atherosclerotic properties. The study was conducted using three groups of animals: having a standard diet, a diet containing 1.0\% cholesterol, and having a diet with $1.0 \%$ cholesterol with oxysterols. After 2 weeks of supplementation, the levels of oxysterols in the plasma of both groups with a cholesterol diet were significantly elevated. In addition, the cholesterol content in the aortas in the group supplemented with cholesterol and oxysterols was more than twice higher than in the group supplemented with the addition of cholesterol. However, there were no visible atherosclerotic changes in carotid and abdominal aortas in all groups. Based on the received results, Vine et al. concluded that oxysterols do not possess atherosclerotic properties. However, according to the disease mechanism, first the production of lesions and a subsequent progression of oxysterols is needed. For this study such properties cannot be investigated within 2 weeks of the administration of an oxidized form of cholesterol. It is also noticeable that animals were administrated with a mixture formed after cholesterol heating, which contained cholest-4-ene3-one, which technically is not an oxysterol.

Another study investigating the properties of oxysterols was performed by Ando et al., (2002) [132]. Studies 
were conducted using apo: ${ }^{-/-}$mice, which were divided into three groups, each on a different diet - control diet, a diet containing cholesterol and a diet containing oxysterols. After 11 weeks the size of the atherosclerotic lesions in aortas was examined and there was no statistically significant difference between all groups, which leads to the conclusion that oxysterols do not possess atherosclerotic properties. As mentioned in the previously described studies, also in this one, oxysterols were produced by heating cholesterol above $100{ }^{\circ} \mathrm{C}$ without any purifying process, which was a reason of obtaining about $20 \%$ of unknown compounds in the oxysterol mixture. Furthermore, mice chow contained t-butyl hydroquinone, which acts as an antioxidant, which raises a question whether it is possible to protect LDL from oxidation and by this protect mice from lesion formation.

$\mathrm{ApoE}^{-1-}$ mice were also used in a study conducted by Weingärtner et al., (2015) [133]. Animals were divided into three groups: a placebo group (dextran emulsion), a group administered with cholesterol and a group administered with $7 \beta-\mathrm{hCh}$. All groups had a Western-type diet containing $0.15 \%(w / w)$ cholesterol. After 4 weeks of cholesterol and $7 \beta$-hCh by i.p. application, no differences were observed in the number and severity of atherosclerotic lesions in all groups. The study made by Weingärtner et al. (2015) is unique, which makes the obtained result difficult to compare to other available in vivo research. Unfortunately, there is no data in the description concerning the concentration of cholesterol or oxysterol that was administered to the mice. Therefore at this point, it is unclear, if the animals were treated only with pure oxysterol or mixture, again with unknown compounds. Additionally, obtained result cannot be used to draw a conclusion about atherosclerotic properties of other remaining oxysterols, which during heating occur in larger quantities than $7 \beta-h C h$. On the other hand, this result could give researchers an idea to study in vivo only one selected oxysterol.

Heating cholesterol to a high temperature, is, for certain, the simplest way of generating oxysterols, however according to available data, analysing the mechanism of cholesterol oxidation, thermal treatment causes the formation of a large number of compounds from cholesterol, including cholestadienes (technically not oxysterols) - which was mentioned only in one study conducted by Vine et al., (1998) [101], fragmented cholesterol $(3 \beta, 17,21 \alpha$-pregn-ene, ether of $7 \alpha$-hydro

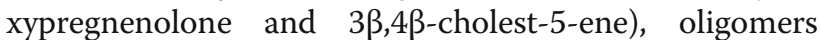
(dimmers, trimers), volatile compound molecules (aldehydes, e.g., 3-methyl-butanal, ketones, e.g., 2-pentanone, alcohols, e.g., 3,4-dimethyl-1-pentanol, hydrocarbons, e.g., 2-methyl-4-decene, esters, e.g., hexanoic acid) (Fig. 4) [134, 135].

Due to the fact that in every in vivo study, oxysterols administered to animals were prepared by heating cholesterol at high temperatures, which in fact resulted in the formation of a mixture of oxysterols with compounds of unknown structure and properties, a final and

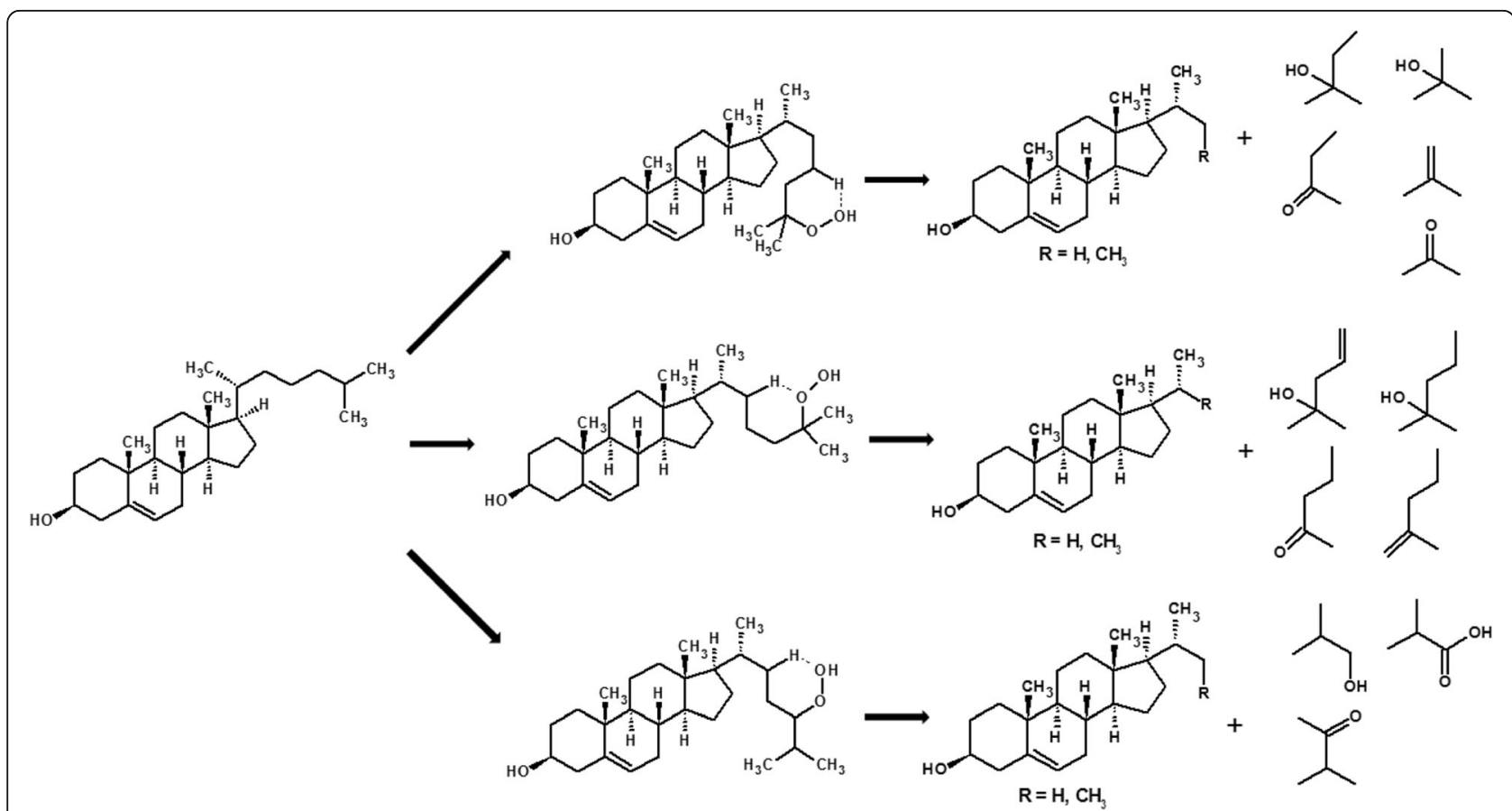

Fig. 4 Example of non-typical cholesterol modification due to the peroxidation of the side chain, which causes the formation of volatile compounds and a cholesterol derivative, which could possibly undergo another oxidation 
definitive conclusion about pro-atherosclerotic properties of oxysterols should not be drawn. Therefore, the study with animals ought to be carried out after the purifying process of oxysterols to ensure that the animals are fed only with the oxidized forms of cholesterol in a suitable proportion, mimicking their content in food. Only one study conducted by Higley et al., (1986) [131] used a mixture of oxysterols after a purification process, using the preparative HPLC. Even after using chromatography some unknown compounds were still present. Based on presented and analysed data, researches of oxysterols properties in in vivo studies should aim towards a new path - using mixtures of oxysterols after suitable purification process or using oxysterols from synthesis or from commercially available vendors. Not only animals were treated with unknown compounds, but the composition of oxysterols mixture in every study was different. It is possible that not every oxysterol has atherosclerotic properties. Additionally it is also possible that the atherosclerotic effect was found, because of the synergetic effect of oxidized forms [98], which can be various when composition of the mixture also differs. Furthermore time of the administration of oxysterols to animals differed from 2 weeks to 7 months, which is probably due to different animal models. Some animal models are atherosusceptible like some rabbit strains, which exhibit familial hypercholesterolemia or wild type mouse strains, which have much more rapid heart rate hence disturbed laminar blood flow is more possible [136]. However the most frequently used models in study of atherosclerosis are the genetic modified apoE ${ }^{-/-}$and the $\mathrm{LDLR}^{-/-}$mouse model [137]. Genetic modification in $\mathrm{apoE}^{-/-}$strain resulted in shortened time, in which animals develop atherosclerotic lesions [138]. However, even for the same animal model, experiment time for determination of oxysterols properties, in the two studies conducted by Staprans et al., (2000) [125] and Weingärtner et al., (2015) [133], differed by up to 12 weeks, which may explain obtained opposite results. In addition, not only the choice of animal model is important for studies, but also the choice of the animal diet [136]. Due to the fact that in each of the mentioned in vivo, diet of control group is different, it causes the irregularity of the comparison of these results. Diet chosen for animal control group should be standard or western type chow, which could result in negligence of different times of the oxysterols exposure.

Different model, time of the experiment, different animals chow and the administrated oxysterol/oxysterol mixture in each of in vivo study, are reasons why obtained results should be considered only individually, which makes the final conclusion of atherosclerotic properties of each oxysterols not possible to draw.

\section{Conclusions/closing remarks}

Heart diseases, cellular aging vessel walls can promote turbulence in the laminar blood flow and the formation of atherosclerotic plaques, which is only the final result of a complex and self-perpetuating cell response to this mechanical stress. For this reason, finding factors, which may cause faster progression of already formed changes seems to be appropriate.

Based on the mechanism of atherosclerotic lesion formation and mentioned in vitro and in vivo studies, it is possible that oxidized forms of cholesterol are one of the factors, which accelerate growth that has already been in the vessel wall and have less effect to cause the initiation of the disease. Such hypothesis needs to be tested in vivo after administration of an oxysterol or oxysterols mixtures only after suitable lesion formation, using e.g. Western type diet. Such approach was applied by Plat et al., (2014) [128] and could confirm this assumption; however, as mentioned, the use of high temperature process cholesterol without a purification process, makes the conclusion of the study doubtful.

As it was mentioned, the amount of consumed oxysterols by human could be relatively high (even $6 \%$ of total cholesterol content). Therefore, elimination of oxysterols content in a diet may not be possible, but it could be minimized by reducing the consumption of cooked cholesterol-rich food, especially after processed by methods, which use high temperatures. Therefore, it is highly desirable to conduct a study that could ultimately determine whether oxysterols actually possess properties to accelerate the growth of atherosclerosis lesions. If such properties are confirmed, it will cause a significant impact on the patient diet with diagnosed atherosclerosis.

\section{Abbreviations}

24-hCh: 24-hydroxycholesterol; 25-hCh: 25-hydroxycholesterol; 27-hCh: 27-hydroxycholesterol; 7-kCh: 7-ketocholesterol; 7a-hCh: 7a-

hydroksycholesterol; 7ß-hCh: 7ß-hydroksycholesterol; ACAT: acylCoA:cholesterol ester transferase; ADMA: Asymmetric dimethylarginine; apoB: Apolipoprotein B; apoE: Apolipoprotein E; CCL5: Chemokine ligand 5; CE: Cholesterol ester; EC: Endothelial cells; eNOS: Endothelium nitric oxide synthase; G-CSF: Granulocyte-colony stimulating factor; ICAM-1: Intercellular Adhesion Molecule 1; IL: Interleukine; LDL: Low density lipoprotein; MCP-1 (CCL2): Monocyte Chemoattractant Protein 1; M-CSF: Macrophage colonystimulating factor; mmLDL: Minimally oxidized low density lipoprotein; MPO: Myeloperoxidase; NF-kB: Nuclear factor kappa-light-chain-enhancer of activated B cells; NO: Nitric oxide; oxLDL: Highly oxidized low density lipoprotein; PC: Phosphatidylcholine; PCAM-1: Platelet endothelial cell adhesion molecule 1; ROS: Reactive oxygen species; SMase: Secretory sphingomyelinase; SPLA2: Secretory phospholipase 2; SR-A: Scavenger receptor type A; TG: Triglyceride; TGF- $\beta$ : Transforming growth factor beta; TNFa: Tumor necrosis factor $\alpha$; triolCh: $5 a$-cholestane-3 $\beta, 5,6 \beta$-triol; VCAM1: Vascular cell adhesion molecule 1; VE-cadherin: Vascular endothelial cadherin; VEGFR2: Vascular endothelial growth factor receptor 2; VLDL: Very low density lipoprotein; VSMC: Vascular Smooth muscle cell; $\alpha$ -

epoxCh: Cholesterol-5a,6a-epoxide; $\beta$-epoxCh: Cholesterol-5 $\beta, 6 \beta$-epoxide

Acknowledgements

Not applicable. 


\section{Funding}

Not applicable.

\section{Availability of data and materials}

Not applicable.

\section{Authors' contributions}

Both authors contributed equally to this work and have read and approved the final manuscript.

\section{Ethics approval and consent to participate}

Not applicable.

\section{Consent for publication}

Not applicable.

\section{Competing interests}

The authors declare that they have no competing interests.

\section{Publisher's Note}

Springer Nature remains neutral with regard to jurisdictional claims in published maps and institutional affiliations.

Received: 28 June 2017 Accepted: 22 September 2017 Published online: 02 October 2017

References:

1. Rubin JB, Borden WB. Coronary heart disease in young adults. Curr Atheroscler Rep. 2012;14:140-9.

2. Lichtenstein AH, Appel LJ, Brands M, Carnethon M, Daniels S, Franch HA, et al. Summary of American Heart Association Diet and Lifestyle Recommendations revision 2006. Arterioscler Thromb Vasc Biol. 2006;26:2186-91

3. Peng SK, Hu B, Morin RJ. Angiotoxicity and atherogenicity of cholestero oxides. J Clin Lab Anal. 1991;5:144-52.

4. Angulo AJ, Romera JM, Ramirez M, Gil A. Determination of Cholesterol Oxides in Dairy Products. Effect of Storage Conditions. J Agric Food Chem. 1997:45:4318-23.

5. Brown AJ, Dean RT, Jessup W. Free and esterified oxysterol: formation during copper-oxidation of low density lipoprotein and uptake by macrophages. J Lipid Res. 1996;37:320-35.

6. Boselli E, Velazco V, Fiorenza Caboni M, Lercker G. Pressurized liquid extraction of lipids for the determination of oxysterols in egg-containing food. J Chromatogr A. 2001:917:239-44.

7. Derewiaka D, Obiedziński M. Cholesterol oxides content in selected anima products determined by GC-MS. Eur J Lipid Sci Technol. 2010;112:1130-7.

8. Jusakul A, Yongvanit P, Loilome W, Namwat N, Kuver R. Mechanisms of oxysterol-induced carcinogenesis. Lipids Health Dis. 2011:10:44.

9. Szterk A, Pakuła L. New method to determine free sterols/oxysterols in food matrices using gas chromatography and ion trap mass spectrometry (GC-IT-MS). Talanta. 2016;152:54-75

10. Wentzel JJ, Chatzizisis YS, Gijsen FJH, Giannoglou GD, Feldman CL, Stone $\mathrm{PH}$. Endothelial shear stress in the evolution of coronary atherosclerotic plaque and vascular remodelling: current understanding and remaining questions. Cardiovasc Res. 2012;96:234-43.

11. DeBakey ME, Lawrie GM, Glaeser DH. Patterns of atherosclerosis and their surgical significance. Ann Surg. 1985;201:115-31.

12. Tzima E, Irani-Tehrani M, Kiosses WB, Dejana E, Schultz DA, Engelhardt B, et al. A mechanosensory complex that mediates the endothelial cell response to fluid shear stress. Nature. 2005;437:426-31.

13. Zaragoza C, Márquez S, Saura M. Endothelial mechanosensors of shear stress as regulators of atherogenesis. Curr Opin Lipidol. 2012;23:446-52.

14. Oeckinghaus A, Ghosh S. The NF-kappaB family of transcription factors and its regulation. Cold Spring Harb Perspect Biol. 2009;1:a000034.

15. Gareus R, Kotsaki E, Xanthoulea S, van der Made I, Gijbels MJJ, Kardakaris R, et al. Endothelial cell-specific NF-kappaB inhibition protects mice from atherosclerosis. Cell Metab. 2008;8:372-83.

16. Kanters E, Pasparakis M, Gijbels MJJ, Vergouwe MN, Partouns-Hendriks I, Fijneman RJA, et al. Inhibition of NF-kB activation in macrophages increases atherosclerosis in LDL receptor-deficient mice. J Clin Invest. 2003;112:1176-85
17. Tarbell JM, Pahakis MY. Mechanotransduction and the glycocalyx. J Intern Med. 2006:259:339-50.

18. Esterbauer $H$, Gebicki J, Puhl H, Jürgens $G$. The role of lipid peroxidation and antioxidants in oxidative modification of LDL. Free Radic Biol Med. 1992:13:341-90

19. Steinberg D. Atherogenesis in perspective: hypercholesterolemia and inflammation as partners in crime. Nat Med. 2002;8:1211-7.

20. Vasile $\mathrm{E}$, Simionescu M, Simionescu N. Visualization of the binding, endocytosis, and transcytosis of low-density lipoprotein in the arterial endothelium in situ. J Cell Biol. 1983;96:1677-89.

21. Snelting-Havinga I, Mommaas M, Van Hinsbergh WW, Daha MR, Daems WT, Vermeer BJ. Immunoelectron microscopic visualization of the transcytosis of low density lipoproteins in perfused rat arteries. Eur J Cell Biol. 1989:48:27-36.

22. Weinbaum S, Tzeghai G, Ganatos P, Pfeffer R, Chien S. Effect of cell turnover and leaky junctions on arterial macromolecular transport. Am J Phys. 1985;248:H945-60

23. Yang N, Vafai K. Modeling of low-density lipoprotein (LDL) transport in the artery_effects of hypertension. Int J Heat Mass Transf. 2006;49:850-67.

24. Yang N, Vafai K. Low-density lipoprotein (LDL) transport in an artery - A simplified analytical solution. Int J Heat Mass Transf. 2008;51:497-505.

25. Wiklund O, Carew TE, Steinberg D. Role of the low density lipoprotein receptor in penetration of low density lipoprotein into rabbit aortic wall. Arterioscler Dallas Tex. 1985:5:135-41.

26. Stender $\mathrm{S}$. The in vivo transfer of free and esterified cholesterol from plasma into the arterial wall of hypercholesterolemic rabbits. Scand J Clin Lab Investig Suppl. 1982;161:43-52.

27. Rajman I, Eacho PI, Chowienczyk PJ, Ritter JM. LDL particle size: an important drug target? Br J Clin Pharmacol. 1999;48:125-33.

28. Hurt-Camejo E, Camejo G, Sartipy P. Phospholipase A2 and small, dense low-density lipoprotein. Curr Opin Lipidol. 2000:11:465-71.

29. Kokkonen JO, Kovanen PT. Proteolytic enzymes of mast cell granules degrade low density lipoproteins and promote their granule-mediated uptake by macrophages in vitro. J Biol Chem. 1989;264:10749-55.

30. Oörni K, Hakala JK, Annila A, Ala-Korpela M, Kovanen PT. Sphingomyelinase induces aggregation and fusion, but phospholipase A2 only aggregation, of low density lipoprotein (LDL) particles. Two distinct mechanisms leading to increased binding strength of LDL to human aortic proteoglycans. Biol Chem. 1998:273:29127-34

31. Oörni K, Pentikäinen MO, Ala-Korpela M, Kovanen PT. Aggregation, fusion, and vesicle formation of modified low density lipoprotein particles: molecular mechanisms and effects on matrix interactions. J Lipid Res. 2000;41:1703-14.

32. Plüddemann A, Neyen C, Gordon S. Macrophage scavenger receptors and host-derived ligands. Methods San Diego Calif. 2007:43:207-17.

33. Abdul Zani I, Stephen SL, Mughal NA, Russell D, Homer-Vanniasinkam S, Wheatcroft SB, et al. Scavenger Receptor Structure and Function in Health and Disease. Cell. 2015;4:178-201.

34. Collot-Teixeira S, Martin J, McDermott-Roe C, Poston R, McGregor JL. CD36 and macrophages in atherosclerosis. Cardiovasc Res. 2007;75:468-77.

35. Levitan I, Volkov S, Subbaiah PV. Oxidized LDL: Diversity, Patterns of Recognition, and Pathophysiology. Antioxid Redox Signal. 2010;13:39-75.

36. Stanton LW, White RT, Bryant CM, Protter AA, Endemann G. A macrophage Fc receptor for lgG is also a receptor for oxidized low density lipoprotein. J Biol Chem. 1992;267:22446-51.

37. Li D, Yang B, Philips MI, Mehta JL. Proapoptotic effects of ANG II in human coronary artery endothelial cells: role of AT1 receptor and PKC activation. Am J Phys. 1999;276:H786-92.

38. Chisolm GM, Steinberg D. The oxidative modification hypothesis of atherogenesis: an overview. Free Radic Biol Med. 2000;28:1815-26.

39. Mudau M, Genis A, Lochner A, Strijdom H. Endothelial dysfunction: the early predictor of atherosclerosis. Cardiovasc J Afr. 2012:23:222-31.

40. Durán WN, Breslin JW, Sánchez FA. The NO cascade, eNOS location, and microvascular permeability. Cardiovasc Res. 2010:87:254-61.

41. Napoli C, Paolisso G, Casamassimi A, Al-Omran M, Barbieri M, Sommese L, et al. Effects of Nitric Oxide on Cell Proliferation: Novel Insights. J Am Coll Cardiol. 2013;62:89-95

42. Irwin C, Roberts W, Naseem KM. Nitric oxide inhibits platelet adhesion to collagen through cGMP-dependent and independent mechanisms: the potential role for S-nitrosylation. Platelets. 2009;20:478-86.

43. Armstead VE, Minchenko AG, Schuhl RA, Hayward R, Nossuli T, Lefer AM Regulation of P-selectin expression in human endothelial cells by nitric oxide. Am J Phys. 1997;273:H740-6. 
44. Cyrus T, Witztum JL, Rader DJ, Tangirala R, Fazio S, Linton MF, et al. Disruption of the 12/15-lipoxygenase gene diminishes atherosclerosis in apo E-deficient mice. J Clin Invest. 1999;103:1597-604.

45. George J, Afek A, Shaish A, Levkovitz H, Bloom N, Cyrus T, et al. 12/15Lipoxygenase gene disruption attenuates atherogenesis in $L D L$ receptordeficient mice. Circulation. 2001;104:1646-50.

46. Marathe S, Kuriakose G, Williams KJ, Tabas I. Sphingomyelinase, an enzyme implicated in atherogenesis, is present in atherosclerotic lesions and binds to specific components of the subendothelial extracellular matrix. Arterioscler Thromb Vasc Biol. 1999;19:2648-58.

47. Ivandic B, Castellani LW, Wang XP, Qiao JH, Mehrabian M, Navab M, et al. Role of group II secretory phospholipase A2 in atherosclerosis: 1. Increased atherogenesis and altered lipoproteins in transgenic mice expressing group Ila phospholipase A2. Arterioscler Thromb Vasc Biol. 1999;19:1284-90.

48. Kamanna VS, Ganji SH, Kashyap ML. Myeloperoxidase and Atherosclerosis. Curr Cardiovasc Risk Rep. 2013;7:102-7.

49. Rapp JH, Connor WE, Lin DS, Inahara T, Porter JM. Lipids of human atherosclerotic plaques and xanthomas: clues to the mechanism of plaque progression. J Lipid Res. 1983;24:1329-35.

50. Ylä-Herttuala S, Jaakkola O, Ehnholm C, Tikkanen MJ, Solakivi T, Särkioja T, et al. Characterization of two lipoproteins containing apolipoproteins B and E from lesion-free human aortic intima. J Lipid Res. 1988;29:563-72.

51. Yoshida H, Kisugi R. Mechanisms of LDL oxidation. Clin. Chim. Acta Int. J Clin Chem. 2010;411:1875-82

52. Podrez EA, Poliakov E, Shen Z, Zhang R, Deng Y, Sun M, et al. Identification of a novel family of oxidized phospholipids that serve as ligands for the macrophage scavenger receptor CD36. J Biol Chem. 2002;277:38503-16.

53. Chisolm GM, Ma G, Irwin KC, Martin LL, Gunderson KG, Linberg LF, et al. 7 beta-hydroperoxycholest-5-en-3 beta-ol, a component of human atherosclerotic lesions, is the primary cytotoxin of oxidized human low density lipoprotein. Proc Natl Acad Sci U S A. 1994;91:11452-6.

54. Brown AJ, Leong SL, Dean RT, Jessup W. 7-Hydroperoxycholesterol and its products in oxidized low density lipoprotein and human atherosclerotic plaque. J Lipid Res. 1997;38:1730-45.

55. Knott TJ, Wallis SC, Powell LM, Pease RJ, Lusis AJ, Blackhart B, et al. Complete CDNA and derived protein sequence of human apolipoprotein B-100. Nucleic Acids Res. 1986;14:7501-3.

56. Yang CY, Chen SH, Gianturco SH, Bradley WA, Sparrow JT, Tanimura M, et al. Sequence, structure, receptor-binding domains and internal repeats of human apolipoprotein B-100. Nature. 1986;323:738-42.

57. Hevonoja T, Pentikäinen MO, Hyvönen MT, Kovanen PT, Ala-Korpela M. Structure of low density lipoprotein (LDL) particles: basis for understanding molecular changes in modified LDL. Biochim Biophys Acta. 2000;1488:189-210.

58. Obama T, Kato R, Masuda Y, Takahashi K, Aiuchi T, Itabe H. Analysis of modified apolipoprotein B-100 structures formed in oxidized low-density lipoprotein using LC-MS/MS. Proteomics. 2007;7:2132-41.

59. Chakraborty S, Cai Y, Tarr MA. Mapping oxidations of apolipoprotein B-100 in human low-density lipoprotein by liquid chromatography-tandem mass spectrometry. Anal Biochem. 2010;404:109-17.

60. Segrest JP, Jones MK, De Loof H, Dashti N. Structure of apolipoprotein B-100 in low density lipoproteins. J Lipid Res. 2001;42:1346-67.

61. Chehin R, Rengel D, Milicua JC, Goñi FM, Arrondo JL, Pifat G. Early stages of LDL oxidation: apolipoprotein B structural changes monitored by infrared spectroscopy. J Lipid Res. 2001;42:778-82.

62. Mestas J, Ley K. Monocyte-endothelial cell interactions in the development of atherosclerosis. Trends Cardiovasc Med. 2008;18:228-32.

63. Combadière $C$, Potteaux $S$, Rodero $M$, Simon $T$, Pezard $A$, Esposito $B$, et al. Combined inhibition of CCL2, CX3CR1, and CCR5 abrogates Ly6C(hi) and Ly6C(lo) monocytosis and almost abolishes atherosclerosis in hypercholesterolemic mice. Circulation. 2008;117:1649-57.

64. Reape TJ, Groot PH. Chemokines and atherosclerosis. Atherosclerosis. 1999; $147: 213-25$.

65. Harrington JR. The role of MCP-1 in atherosclerosis. Stem Cells Dayt Ohio. 2000;18:65-6.

66. Kunjathoor W, Febbraio M, Podrez EA, Moore KJ, Andersson L, Koehn S, et al. Scavenger receptors class $A-1 / I I$ and $C D 36$ are the principal receptors responsible for the uptake of modified low density lipoprotein leading to lipid loading in macrophages. J Biol Chem. 2002;277:49982-8.

67. Moore KJ, Kunjathoor W, Koehn SL, Manning JJ, Tseng AA, Silver JM, et al. Loss of receptor-mediated lipid uptake via scavenger receptor A or CD36 pathways does not ameliorate atherosclerosis in hyperlipidemic mice. J Clin Invest. 2005;115:2192-201.

68. Maxfield FR, Tabas I. Role of cholesterol and lipid organization in disease. Nature. 2005:438:612-21.

69. Rothblat GH, Phillips MC. High-density lipoprotein heterogeneity and function in reverse cholesterol transport. Curr Opin Lipidol. 2010;21:229-38.

70. Brown MS, Ho YK, Goldstein JL. The cholesteryl ester cycle in macrophage foam cells. Continual hydrolysis and re-esterification of cytoplasmic cholesteryl esters. J Biol Chem. 1980;255:9344-52.

71. Gelissen IC, Brown AJ, Mander EL, Kritharides L, Dean RT, Jessup W. Sterol efflux is impaired from macrophage foam cells selectively enriched with 7-ketocholesterol. J Biol Chem. 1996;271:17852-60.

72. Maor I, Aviram M. Oxidized low density lipoprotein leads to macrophage accumulation of unesterified cholesterol as a result of lysosomal trapping of the lipoprotein hydrolyzed cholesteryl ester. J Lipid Res. 1994;35:803-19.

73. Brown AJ, Mander EL, Gelissen IC, Kritharides L, Dean RT, Jessup W. Cholesterol and oxysterol metabolism and subcellular distribution in macrophage foam cells. Accumulation of oxidized esters in lysosomes. J. Lipid Res. 2000;41:226-37.

74. Kritharides L, Jessup W, Mander EL, Dean RT. Apolipoprotein A-I-mediated efflux of sterols from oxidized LDL-loaded macrophages. Arterioscler Thromb Vasc Biol. 1995;15:276-89.

75. Accad M, Smith SJ, Newland DL, Sanan DA, King LE, Linton MF, et al. Massive xanthomatosis and altered composition of atherosclerotic lesions in hyperlipidemic mice lacking acyl CoA:cholesterol acyltransferase 1. J Clin Invest. 2000;105:711-9.

76. Rensen SSM, Doevendans PAFM, van Eys GJJM. Regulation and characteristics of vascular smooth muscle cell phenotypic diversity. Neth Heart J. 2007;15:100-8.

77. Gomez D, Owens GK. Smooth muscle cell phenotypic switching in atherosclerosis. Cardiovasc Res. 2012;95:156-64.

78. Viola M, Bartolini B, Vigetti D, Karousou E, Moretto P, Deleonibus S, et al Oxidized Low Density Lipoprotein (LDL) Affects Hyaluronan Synthesis in Human Aortic Smooth Muscle Cells. J Biol Chem. 2013;288:29595-603.

79. Shankman LS, Gomez D, Cherepanova OA, Salmon M, Alencar GF, Haskins RM, et al. KLF4-dependent phenotypic modulation of smooth muscle cells has a key role in atherosclerotic plaque pathogenesis. Nat Med. 2015;21:628-37.

80. Yuan C, Mitsumori LM, Ferguson MS, Polissar NL, Echelard D, Ortiz G, et al. In vivo accuracy of multispectral magnetic resonance imaging for identifying lipid-rich necrotic cores and intraplaque hemorrhage in advanced human carotid plaques. Circulation. 2001;104:2051-6.

81. Watson KE, Boström K, Ravindranath R, Lam T, Norton B, Demer LL. TGFbeta 1 and 25-hydroxycholesterol stimulate osteoblast-like vascular cells to calcify. J Clin Invest. 1994;93:2106-13.

82. Libby P, Ridker PM, Hansson GK. Progress and challenges in translating the biology of atherosclerosis. Nature. 2011;473:317-25.

83. Brzeska M, Szymczyk K, Szterk A. Current Knowledge about Oxysterols: A Review. J Food Sci. 2016;81:R2299-308.

84. Johnson CB. Isolation of cholesterol oxidation products from animal fat using aminopropyl solid-phase extraction. J Chromatogr A. 1996;736:205-10.

85. Min J-S, Khan Ml, Lee S-O, Yim DG, Seol KH, Lee M, et al. Impact of Cooking, Storage, and Reheating Conditions on the Formation of Cholesterol Oxidation Products in Pork Loin. Korean J Food Sci Anim Resour. 2016;36:23-8.

86. Lee SO, Lim DG, Seol KH, Erwanto Y, Lee* M. Effects of Various Cooking and Re-heating Methods on Cholesterol Oxidation Products of Beef Loin. AsianAustralas. J. Anim. Sci. 2006;19:756-62.

87. Olkkonen VM, Gylling H, Ikonen E. Plant sterols, cholesterol precursors and oxysterols: Minute concentrations-Major physiological effects. Biol: J. Steroid Biochem. Mol; 2015

88. Osada K, Sasaki E, Sugano M. Lymphatic absorption of oxidized cholesterol in rats. Lipids. 1994:29:555-9.

89. Linseisen J, Wolfram G. Absorption of cholesterol oxidation products from ordinary foodstuff in humans. Ann Nutr Metab. 1998;42:221-30.

90. Krut LH, Yang JW, Schonfeld G, Ostlund RE. The effect of oxidizing cholesterol on gastrointestinal absorption, plasma clearance, tissue distribution, and processing by endothelial cells. Arterioscler Thromb Vasc Biol. 1997;17:778-85.

91. Vine DF, Croft KD, Beilin L, Mamo JC. Absorption of dietary cholesterol oxidation products and incorporation into rat lymph chylomicrons. Lipids. 1997:32:887-93. 
92. Lin CY, Morel DW. Esterification of oxysterols in human serum: effects on distribution and cellular uptake. J Lipid Res. 1996;37:168-78.

93. Staprans I, Pan X-M, Rapp JH, Feingold KR. Oxidized cholesterol in the diet is a source of oxidized lipoproteins in human serum. J Lipid Res. 2003:44:705-15

94. Babiker A, Diczfalusy U. Transport of side-chain oxidized oxysterols in the human circulation. Biochim Biophys Acta. 1998;1392:333-9.

95. Dzeletovic S, Breuer O, Lund E, Diczfalusy U. Determination of Cholesterol Oxidation Products in Human Plasma by Isotope Dilution-Mass Spectrometry. Anal Biochem. 1995;225:73-80.

96. Crosignani A, Zuin M, Allocca M, Del Puppo M. Oxysterols in bile acid metabolism. Clin Chim Acta. 2011;412:2037-45.

97. Lizard G, Monier S, Cordelet C, Gesquière L, Deckert V, Gueldry S, et al. Characterization and comparison of the mode of cell death, apoptosis versus necrosis, induced by 7 beta-hydroxycholesterol and 7 ketocholesterol in the cells of the vascular wall. Arterioscler Thromb Vasc Biol. 1999;19:1190-200.

98. O'Sullivan AJ, O'Callaghan YC, O'Brien NM. Differential Effects of Mixtures of Cholesterol Oxidation Products on Bovine Aortic Endothelial Cells and Human Monocytic U937 Cells. Int J Toxicol. 2005;24:173-9.

99. Vejux A, Lizard G. Cytotoxic effects of oxysterols associated with human diseases: Induction of cell death (apoptosis and/or oncosis), oxidative and inflammatory activities, and phospholipidosis. Mol Asp Med. 2009;30:153-70

100. Shentu TP, Singh DK, Oh M-J, Sun S, Sadaat L, Makino A, et al. The role of oxysterols in control of endothelial stiffness. J Lipid Res. 2012;53:1348-58.

101. Vine DF, Mamo CL, Beilin L, Mori TA, Croft KD. Dietary oxysterols are incorporated in plasma triglyceride-rich lipoproteins, increase their susceptibility to oxidation and increase aortic cholesterol concentration of rabbits. J Lipid Res. 1998;39:1995-2004.

102. Sato K, Nakano K, Katsuki S, Matoba T, Osada K, Sawamura T, et al. Dietary cholesterol oxidation products accelerate plaque destabilization and rupture associated with monocyte infiltration/activation via the MCP-1-CCR2 pathway in mouse brachiocephalic arteries: therapeutic effects of ezetimibe. J Atheroscler Thromb. 2012;19:986-98.

103. Gargiulo S, Testa G, Gamba P, Staurenghi E, Poli G, Leonarduzzi G. Oxysterols and 4-hydroxy-2-nonenal contribute to atherosclerotic plaque destabilization. Free Radical Biology and Medicine. 2017;111:140-50.

104. Lizard G, Deckert V, Dubrez L, Moisant M, Gambert P, Lagrost L. Induction of apoptosis in endothelial cells treated with cholesterol oxides. Am J Pathol. 1996;148:1625-38.

105. Yuan XM, Li W, Brunk UT, Dalen H, Chang YH, Sevanian A. Lysosomal destabilization during macrophage damage induced by cholesterol oxidation products. Free Radic Biol Med. 2000;28:208-18.

106. Ares MPS, Pörn-Ares MI, Moses S, Thyberg J, Juntti-Berggren L, Berggren P-O, et al. 7ß-Hydroxycholesterol induces Ca2+ oscillations, MAP kinase activation and apoptosis in human aortic smooth muscle cells. Atherosclerosis. 2000;153:23-35.

107. Aupeix K, Weltin D, Mejia JE, Christ M, Marchal J, Freyssinet J-M, et al. Oxysterol-induced Apoptosis in Human Monocytic Cell Lines. Immunobiology. 1995;194:415-28.

108. Ryan L, O'Callaghan YC, O'Brien NM. Generation of an oxidative stress precedes caspase activation during $7 \beta$-hydroxycholesterol-induced apoptosis in U937 cells. J Biochem Mol Toxicol. 2004;18:50-9.

109. Lizard G, Gueldry S, Sordet O, Monier S, Athias A, Miguet C, et al. Glutathione is implied in the control of 7-ketocholesterol-induced apoptosis, which is associated with radical oxygen species production. FASEB J. Off. Publ. Fed. Am. Soc. Exp. Biol. 1998;12:1651-63.

110. Lizard G, Miguet C, Besséde G, Monier S, Gueldry S, Neel D, et al. Impairment with various antioxidants of the loss of mitochondrial transmembrane potential and of the cytosolic release of cytochrome c occuring during 7-ketocholesterol-induced apoptosis. Free Radic Biol Med. 2000;28:743-53.

111. Miguet C, Monier S, Bettaieb A, Athias A, Besséde G, Laubriet A, et al. Ceramide generation occurring during 7 beta-hydroxycholesterol- and 7-ketocholesterol-induced apoptosis is caspase independent and is not required to trigger cell death. Cell Death Differ. 2001;8:83-99.

112. Seye Cl, Knaapen MWM, Daret D, Desgranges C, Herman AG, Kockx MM, et al. 7-Ketocholesterol induces reversible cytochrome $\mathrm{c}$ release in smooth muscle cells in absence of mitochondrial swelling. Cardiovasc Res. 2004;64:144-53.
113. Ryan L, O'Callaghan YC, O'Brien NM. The role of the mitochondria in apoptosis induced by $7 \beta$-hydroxycholesterol and cholesterol-5 $3,6 \beta$-epoxide. Br. J. Nutr. 2005;94:519-25.

114. Yang L, Sinensky MS. 25-Hydroxycholesterol activates a cytochrome c release-mediated caspase cascade. Biochem Biophys Res Commun. 2000;278:557-63.

115. Nishio E, Watanabe Y. Oxysterols induced apoptosis in cultured smooth muscle cells through CPP32 protease activation and bcl-2 protein downregulation. Biochem Biophys Res Commun. 1996;226:928-34.

116. Lim H-K, Kang H-K, Yoo E-S, Kim B-J, Kim Y-W, Cho M, et al. Oxysterols induce apoptosis and accumulation of cell cycle at G2/M phase in the human monocytic THP-1 cell line. Life Sci. 2003;72:1389-99.

117. Prunet C, Lemaire-Ewing S, Ménétrier F, Néel D, Lizard G. Activation of caspase-3-dependent and -independent pathways during 7-ketocholesteroland 7beta-hydroxycholesterol-induced cell death: a morphological and biochemical study. J Biochem Mol Toxicol. 2005;19:311-26.

118. Larsson DA, Baird S, Nyhalah JD, Yuan X-M, Li W. Oxysterol mixtures, in atheroma-relevant proportions, display synergistic and proapoptotic effects. Free Radic Biol Med. 2006;41:902-10.

119. Biasi F, Leonarduzzi G, Vizio B, Zanetti D, Sevanian A, Sottero B, et al. Oxysterol mixtures prevent proapoptotic effects of 7-ketocholesterol in macrophages: implications for proatherogenic gene modulation. FASEB J. Off Publ Fed Am Soc Exp Biol. 2004;18:693-5.

120. Leonarduzzi G, Biasi F, Chiarpotto E, Poli G. Trojan horse-like behavior of a biologically representative mixture of oxysterols. Mol Asp Med. 2004;25:155-67.

121. Brown AJ, Jessup W. Oxysterols and atherosclerosis. Atherosclerosis. 1999; 142:1-28.

122. Jacobson MS, Price MG, Shamoo AE, Heald FP. Atherogenesis in white carneau pigeons. Effects of low-level cholestane-triol feeding. Atherosclerosis. 1985;57:209-17.

123. Mahfouz MM, Kawano H, Kummerow FA. Effect of cholesterol-rich diets with and without added vitamins $E$ and $C$ on the severity of atherosclerosis in rabbits. Am J Clin Nutr. 1997;66:1240-9.

124. Poirot M, Silvente-Poirot S. Cholesterol-5,6-epoxides: chemistry, biochemistry, metabolic fate and cancer. Biochimie. 2013;95:622-31.

125. Staprans I, Pan XM, Rapp JH, Grunfeld C, Feingold KR. Oxidized cholesterol in the diet accelerates the development of atherosclerosis in LDL receptorand apolipoprotein E-deficient mice. Arterioscler Thromb Vasc Biol. 2000;20:708-14.

126. Staprans I, Pan XM, Rapp JH, Feingold KR. Oxidized cholesterol in the diet accelerates the development of aortic atherosclerosis in cholesterol-fed rabbits. Arterioscler Thromb Vasc Biol. 1998;18:977-83.

127. Meynier A, Lherminier J, Demaison-Meloche J, Ginies C, Grandgirard A, Demaison L. Effects of dietary oxysterols on coronary arteries in hyperlipidaemic hamsters. Br J Nutr. 2002;87:447-58.

128. Plat J, Theuwissen E, Husche C, Lütjohann D, Gijbels MJJ, Jeurissen M, et al. Oxidised plant sterols as well as oxycholesterol increase the proportion of severe atherosclerotic lesions in female LDL receptor+/- mice. Br J Nutr. 2014;111:64-70.

129. Umetani M, Ghosh P, Ishikawa T, Umetani J, Ahmed M, Mineo C, et al. The cholesterol metabolite 27-hydroxycholesterol promotes atherosclerosis via proinflammatory processes mediated by estrogen receptor alpha. Cell Metab. 2014;20:172-82.

130. Nofer J-R. Estrogens and atherosclerosis: insights from animal models and cell systems. J Mol Endocrinol. 2012;48:R13-29.

131. Higley NA, Beery JT, Taylor SL, Porter JW, Dziuba JA, Lalich JJ. Comparative atherogenic effects of cholesterol and cholesterol oxides. Atherosclerosis. 1986;62:91-104

132. Ando M, Tomoyori H, Imaizumi K. Dietary cholesterol-oxidation products accumulate in serum and liver in apolipoprotein E-deficient mice, but do not accelerate atherosclerosis. Br J Nutr. 2002;88:339-45.

133. Weingärtner O, Husche C, Schött HF, Speer T, Böhm M, Miller CM, et al. Vascular effects of oxysterols and oxyphytosterols in apoE -/- mice. Atherosclerosis. 2015;240:73-9.

134. Smith LL. Cholesterol autoxidation 1981-1986. Chem Phys Lipids. 1987:44:87-125

135. Derewiaka D. Molińska (née Sosińska) E. Cholesterol transformations during heat treatment. Food Chem. 2015;171:233-40.

136. Getz GS, Reardon CA. Animal models of atherosclerosis. Arterioscler Thromb Vasc Biol. 2012;32:1104-15. 
137. Véniant MM, Withycombe S, Young SG. Lipoprotein Size and Atherosclerosis Susceptibility in Apoe-/- and Ldlr-/- Mice. Arterioscler Thromb Vasc Biol. 2001:21:1567-70.

138. Nakashima Y, Plump AS, Raines EW, Breslow UL, Ross R. ApoE-deficient mice develop lesions of all phases of atherosclerosis throughout the arterial tree. Arterioscler Thromb Vasc Biol. 1994;14:133-40.

Submit your next manuscript to BioMed Central and we will help you at every step:

- We accept pre-submission inquiries

- Our selector tool helps you to find the most relevant journal

- We provide round the clock customer support

- Convenient online submission

- Thorough peer review

- Inclusion in PubMed and all major indexing services

- Maximum visibility for your research

Submit your manuscript at www.biomedcentral.com/submit 